\title{
Optical Dissection of Odor Information Processing In Vivo Using GCaMPs Expressed in Specified Cell Types of the Olfactory Bulb
}

\author{
Matt Wachowiak, ${ }^{1,2,4}$ Michael N. Economo, ${ }^{2}$ Marta Díaz-Quesada, ${ }^{2}$ Daniela Brunert, ${ }^{2}$ Daniel W. Wesson, ${ }^{4}$ \\ John A. White, ${ }^{2,3}$ and Markus Rothermel ${ }^{2}$ \\ ${ }^{1}$ Department of Neurobiology and Anatomy, University of Utah, Salt Lake City, Utah 84132, ${ }^{2}$ Brain Institute and ${ }^{3}$ Department of Bioengineering, University \\ of Utah, Salt Lake City, Utah 84112, and ${ }^{4}$ Department of Biology, Boston University, Boston, Massachusetts 02215
}

Understanding central processing requires precise monitoring of neural activity across populations of identified neurons in the intact brain. In the present study, we used recently optimized variants of the genetically encoded calcium sensor GCaMP (GCaMP3 and GCaMPG5G) to image activity among genetically and anatomically defined neuronal populations in the olfactory bulb (OB), including two types of GABAergic interneurons (periglomerular [PG] and short axon [SA] cells) and OB output neurons (mitral/tufted [MT] cells) projecting to the piriform cortex. We first established that changes in neuronal spiking can be related accurately to GCaMP fluorescence changes via a simple quantitative relationship over a large dynamic range. We next used in vivo two-photon imaging from individual neurons and epifluorescence signals reflecting population-level activity to investigate the spatiotemporal representation of odorants across these neuron types in anesthetized and awake mice. Under anesthesia, individual PG and SA cells showed temporally simple responses and little spontaneous activity, whereas MT cells were spontaneously active and showed diverse temporal responses. At the population level, response patterns of PG, SA, and MT cells were surprisingly similar to those imaged from sensory inputs, with shared odorant-specific topography across the dorsal OB and inhalation-coupled temporal dynamics. During wakefulness, PG and SA cell responses increased in magnitude but remained temporally simple, whereas those of MT cells changed to complex spatiotemporal patterns reflecting restricted excitation and widespread inhibition. These results suggest multiple circuit elements with distinct roles in transforming odor representations in the $\mathrm{OB}$ and provide a framework for further study of early olfactory processing using optical and genetic tools.

\section{Introduction}

The olfactory bulb $(\mathrm{OB})$ is an obligatory link between sensory input carried by olfactory receptor neurons (ORNs) and brain areas underlying odor perception and thus mediates the initial processing of olfactory information. The OB includes several classes of GABAergic local interneurons, including periglomerular (PG) cells, short axon (SA) cells, and granule cells, at least one class of glutamatergic local interneuron (external tufted cells), and several classes of principal output neurons (mitral/tufted $[\mathrm{MT}]$ cells) (Wachowiak and Shipley, 2006). Understanding how

Received 0ct. 11, 2012; revised Jan. 18, 2013; accepted Feb. 11, 2013.

Author contributions: M.W., M.N.E., D.W.W., and M.R. designed research; M.N.E., M.D.-Q., D.B., D.W.W., and M.R. performed research; J.A.W. and M.R. contributed unpublished reagents/analytical tools; M.W., M.N.E., M.D.-Q., D.B., and M.R. analyzed data; M.W., M.N.E., and M.R. wrote the paper.

This work was supported by the National Institutes of Health (Grants DC06441 and 2DC012718 to M.W.; Grant 1F32DC012718-01 to M.N.E.) and the Deutsche Forschungsgemeinschaft (to M.R.). We thank C. Zabawa for technical support and Drs. Looger, Akerboom, and Kim and the Genetically Encoded Calcium Indicator Project at Janelia Farm Research Campus in collaboration with Penn Vector Core for providing GCaMPexpressing viruses.

The authors declare no competing financial interests.

Correspondence should be addressed to Matt Wachowiak, Brain Institute, Sorenson Molecular Biotechnology Building, 36 S. Wasatch Drive, University of Utah, Salt Lake City, UT 84112. E-mail: matt.wachowiak@utah.edu.

DOI:10.1523/JNEUROSCI.4824-12.2013

Copyright $\odot 2013$ the authors $\quad 0270-6474 / 13 / 335285-16 \$ 15.00 / 0$ sensory inputs drive postsynaptic activity across these circuit elements and how the OB network transforms primary sensory representations is central to understanding mammalian olfactory processing.

Among ORNs, odor representations consist of odorantspecific and temporally dynamic patterns of input to OB glomeruli. Although these input patterns have been well characterized using imaging (Wachowiak and Cohen, 2001; Bozza et al., 2004; Verhagen et al., 2007; Ma et al., 2012), odor representations among defined populations of postsynaptic OB neurons have only begun to be described. Responses of individual MT cells have been characterized extensively using electrophysiological recordings, yet there are few descriptions of how other neuron types respond to odorants (Wellis and Scott, 1990; Tan et al., 2010; Kato et al., 2012). In addition, to compare odor representations at specific stages of processing directly within the OB, it is useful to monitor activity across many neurons of a given cell type under identical conditions, a goal that can be achieved efficiently using optical reporters of neural activity.

A few prior studies imaging postsynaptic odor representations in vivo have relied on voltage-sensitive dyes (Spors et al., 2006) or transgenic GCaMP expression (Chaigneau et al., 2007; Fletcher et al., 2009), approaches that lack clear cell-type specificity. A recent 
report using the genetically encoded $\mathrm{Ca}^{2+}$ sensor GCaMP3 expressed separately in MT and granule cells found a strong divergence in the response properties of these two populations and striking modulation of responsiveness by wakefulness and experience (Kato et al., 2012). How additional OB neuron populations represent odor information and how these representations compare with those of ORN inputs remain unclear.

In the present study, we used recently developed GCaMP variants with improved performance in vivo (Tian et al., 2009; Akerboom et al., 2012) to visualize how odor information is represented among three distinct subpopulations of $\mathrm{OB}$ neurons. We expressed the GCaMP variants GCaMP3 and GCaMP5G selectively in GABAergic PG interneurons, GABAergic and dopaminergic SA cells, and MT cells projecting to specific cortical targets. We also established a reliable quantitative relationship between GCaMP signals and spiking activity in OB neurons, compared spatiotemporal representations of odor information across ORNs, PG, SA, and MT cells, and found that the response properties of each of these neuronal populations are distinct and are differentially modified by anesthesia and wakefulness. Our results establish a framework for the continued study of olfactory information processing circuits in the intact animal.

\section{Materials and Methods}

Animals. Experiments were performed on transgenic mice expressing Cre recombinase (Cre) in defined neuronal populations. For selective expression of the fluorescent calcium indicators GCaMP3 and GCaMP5G, mice were either crossed to the Ai38 GCaMP3 reporter line or injected with a viral vector (see below). The mouse strains used were as follows: GAD2-IRES-Cre (Taniguchi et al., 2011), JAX Stock \#010802 (The Jackson Laboratory); TH-Cre, JAX Stock \#008601 (The Jackson Laboratory); PCdh21-Cre (Nagai et al., 2005), The GENSAT Project (Gong et al., 2007), Stock \#030952-UCD (Mutant Mouse Regional Resource Centers); Ai38 (Zariwala et al., 2012), JAX Stock \#014538 (The Jackson Laboratory); Ai9 (Madisen et al., 2010), JAX Stock \#007905 (The Jackson Laboratory); and olfactory marker protein (OMP)synaptopHluorin (spH; Bozza et al., 2004), JAX Stock \#4946 (The Jackson Laboratory), backcrossed into an albino B6 background (JAX Stock $\# 000058$; The Jackson Laboratory). Mice used for OMP-spH imaging were heterozygous for the OMP-spH allele. All animals were $<6$ months of age by completion of data collection. Mice were housed up to three per cage and kept on a 12/12 h light/dark cycle. Food and water was available ad libitum except while the animals were restrained for imaging. All procedures were performed following National Institutes of Health Guide for the Care and Use of Laboratory Animals and were approved by the University of Utah institutional animal care and use committee.

Viral vector expression. Viral vectors driving Cre-dependent expression of GCaMP3 (Tian et al., 2009) or GCaMP5G (Akerboom et al., 2012) were obtained from the University of Pennsylvania Vector Core (AAV2/1 serotype) and injected either directly into the dorsal $\mathrm{OB}$ or in designated targets within the primary olfactory cortex. All mice used for virus injection were homozygous for the allele driving Cre expression. For injection, mice were anesthetized with ketamine (70 $\mathrm{mg} / \mathrm{kg}$ ) and medetomidine (Domitor, $1 \mathrm{mg} / \mathrm{kg}$; Pfizer), placed in a stereotaxic headholder, and a circular craniotomy $(\sim 1 \mathrm{~mm})$ was made over the injection site. Dorsal OB injections were performed using glass pipettes lowered to a depth of 200-300 $\mu \mathrm{m}$; injections into anterior piriform cortex (aPC) used 33 gauge metal needles positioned at (in millimeters relative to bregma): $2.34 \mathrm{AP},+1.5 \mathrm{LM},-3.125 \mathrm{DV}$; medial amygdala. Virus was injected using a programmable syringe controller (QSI, Stoelting) at a rate of $0.1 \mu \mathrm{l} / \mathrm{min}$. Large volumes of virus $(0.5-1 \mu \mathrm{l})$ were injected to achieve widespread infection. Mice received atipamezole (Antisedan, $1 \mathrm{mg} / \mathrm{kg}$ s.c.; Pfizer) at the end of surgery to antagonize the medetomidine-induced effects and to accelerate recovery from anesthesia. Mice were given carprofen (Rimadyl, $5 \mathrm{mg} / \mathrm{kg}$; Pfizer) as an analgesic immediately before surgery, and carprofen-supplemented food (2 mg/ tablet) was provided for $4 \mathrm{~d}$ after surgery. Mice were single housed after surgery and typically imaged $14-28 \mathrm{~d}$ after virus injection.

In vitro imaging and electrophysiology. OB slices were prepared from adult mice according to established techniques. Briefly, mice were anesthetized with isoflurane and decapitated. The brain was removed while submerged in ice-cold, oxygenated artificial CSF containing the following (in mM): $125 \mathrm{NaCl}, 25 \mathrm{NaHCO}_{3}, 25 \mathrm{D}$-glucose, $2.5 \mathrm{KCl}, 2 \mathrm{CaCl}_{2}, 1.25$ $\mathrm{NaH}_{2} \mathrm{PO}_{4}$, and $1 \mathrm{MgCl}_{2}$ (buffered to $\mathrm{pH} 7.4$ with $95 \% \mathrm{O}_{2} / 5 \% \mathrm{CO}_{2}$ ). Sagittal slices of the OB were cut at a thickness of $300 \mu \mathrm{m}$ with a vibrating microtome (VT1200; Leica). After a $>1$ h incubation at room temperature $\left(\sim 22^{\circ} \mathrm{C}\right)$, slices were transferred to the stage of a custom-built microscope equipped with bright-field and two-photon fluorescence optics. Two- to $4 \mathrm{M} \Omega$ glass electrodes were drawn on a horizontal puller (P97; Sutter Instruments) and filled with an intracellular solution consisting of the following (in $\mathrm{mm}$ ): $120 \mathrm{~K}$-gluconate, $20 \mathrm{KCl}, 10 \mathrm{HEPES}, 7$ diTrisPhCr, 4 Na2ATP, 2 MgCl2, 0.3 Tris-GTP, 0.2 EGTA, and buffered to $\mathrm{pH} 7.3$ with $\mathrm{KOH}$ (Sigma-Aldrich). The internal solution contained $0.6 \%$ biocytin (Invitrogen) by weight in some experiments. Electrophysiological recordings were performed with a current-clamp amplifier (Multiclamp 700A; Molecular Devices), and data were acquired using RTXI software (www.rtxi.org). All recordings were conducted at $33^{\circ} \mathrm{C}$. Fluorescence imaging was performed using targeted path scanning (Lillis et al., 2008) implemented on a custom-built two-photon microscope using a pulsed Ti:Sapphire laser (Chameleon Ultra II; Coherent) as a light source. Imaging was performed with a $20 \times, 0.95$ numerical aperture (NA) objective (Olympus), and emitted fluorescence was filtered with a $520 / 65 \mathrm{~nm}$ emission filter (Semrock) and collected with low-noise photomultiplier tubes (H7360-01; Hamamatsu). Path scan rates depended on scan geometry in individual experiments, but ranged from 40 to $150 \mathrm{~Hz}$.

Analysis of in vitro imaging data. All analyses were performed using custom scripts written with MATLAB. Regions of interest along path scans were determined manually and pixels within each region were weighted equally. Fluorescence time series were low-pass filtered using a fourth-order Butterworth filter with a cutoff frequency of $10 \mathrm{~Hz}$ and converted to $\Delta F / F$ according to $\Delta F / F=\left(F-F_{0}\right) / F_{0}$, where $F_{0}$ was taken to be the mean fluorescence over each trial. Linear photobleaching trends were manually subtracted from raw data in a small number of experiments. Spike rate waveforms were computed by convolving binary spike trains with a double exponential function of the form $\exp \left(-t / t_{\text {off }}\right)-$ $\exp \left(-t / t_{\text {on }}\right)$ normalized to have unitary area. Correlation coefficients represent the fraction of variance explained by a linear model constrained to intersect the origin. Brute-force parameter searches were performed at resolutions of 1 and $10 \mathrm{~ms}$ for rise and decay times, respectively. Exponents were determined using the nlinfit function in MATLAB. Peak error was calculated as the fractional difference between the maximal spike rate and the maximal fluorescence averaged over a 200 $\mathrm{ms}$ time window around the peak of the fluorescence for each current step.

Olfactometry. Odorants were presented as dilutions from saturated vapor in cleaned, humidified air using a custom olfactometer under computer control (Bozza et al., 2004; Verhagen et al., 2007). Odorants were typically presented for $4 \mathrm{~s}$. All odorants were obtained at $95-99 \%$ purity from Sigma-Aldrich and stored under nitrogen. The concentration of the odorants ranged from $0.1 \%$ to $2 \%$ saturated vapor.

In vivo two photon imaging. Animals were prepared for two-photon imaging in the same manner as described for wide-field imaging experiments, except that a craniotomy covering $\sim 1 / 2$ of the dorsal surface of the $\mathrm{OB}$ was performed and covered with $2.5 \%$ low-melting-point agarose in Ringer's solution and a glass coverslip. Imaging was performed with a two-photon microscope (MOM; Sutter Instruments) coupled to a pulsed Ti:Sapphire laser (Mai Tai HP; Spectra-Physics) and controlled by Scanimage 3.7 (Pologruto et al., 2003). In all experiments, imaging was performed through a $20 \times 0.95 \mathrm{NA}$ objective and emitted light was collected by multialkali photomultiplier tubes (R6357; Hamamatsu). Fluorescence videos were acquired at $7.5 \mathrm{~Hz}$ in most experiments. Fluorescence time series were extracted and analyzed with custom MATLAB scripts. In all cases, $\Delta F / F$ was calculated as in in vitro experiments. Pseudocolor glomerular-level activation maps reflect single trials in which videos were 
spatially filtered using a Gaussian window with a SD of 1.25 pixels and temporally filtered using a fourth-order Butterworth filter with a cutoff frequency of $0.25 \mathrm{~Hz}$.

Epifluorescence imaging. For acute in vivo experiments, mice were anesthetized with pentobarbital $(50 \mathrm{mg} / \mathrm{kg})$ or isoflurane $\left(0.5-2 \%\right.$ in $\left.\mathrm{O}_{2}\right)$. There was no difference observed between the response properties measured under these two anesthetics, so the data were pooled. Body temperature and heart rate were maintained at $37^{\circ} \mathrm{C}$ and $\sim 400$ beats per minute. Unless otherwise stated, a double tracheotomy was performed and an artificial inhalation paradigm used (Wachowiak and Cohen, 2001; Spors et al., 2006); isoflurane was delivered directly to the tracheotomy tube, bypassing the nasal cavity. Animals were secured in a custom head holder or a stereotaxic device (Kopf Instruments) for further procedures and imaging, which followed previously established protocols (Wachowiak and Cohen, 2001; Bozza et al., 2004; Spors et al., 2006). Imaging in awake, head-fixed mice was performed using an identical optical setup that accommodated a custom restraint and behavioral training apparatus (described below). Wide-field epifluorescence signals were acquired either through thinned bone or after removal of the bone overlying the dorsal OB. The optical setup included an Olympus BX51 illumination turret, an Olympus $4 \times 0.28$ NA objective, a filter set optimized for GFP (exciter: HQ480/40, dichroic: Q505LP, emitter: HQ535/ 50; Semrock), and a $470 \mathrm{~nm}$ LED source (Thorlabs) or 150W Xenon arc lamp (Opti-quip). Light was attenuated using neutral density filters. Optical signals were acquired at a $256 \times 256$ pixel resolution and a frame rate of $25 \mathrm{~Hz}$ ( $7 \mathrm{~Hz}$ for OMP-spH mice) and digitized at 14-bit resolution using a back-illuminated CCD camera (NeuroCCD, SM-256; RedShirtImaging), then synchronized with other experimental signals (respiration, odor control) and stored to disk using Neuroplex software (RedShirtImaging).

For experiments with different anesthesia levels (Fig. 9), animals were maintained on $0.5 \%$ isoflurane during the preparation. Recordings were started after an equilibration phase of $1 \mathrm{~min}$ (for $1 \%$ isoflurane) or were made immediately after adjusting the isoflurane level to $0 \%$ or $2 \%$. Levels were returned to $0.5 \%$ immediately after data acquisition-typically after $<1 \mathrm{~min}$.

Awake, head-fixed preparation. Epifluorescence imaging in awake, head-fixed mice was adapted from our previously published procedures in rats (Verhagen et al., 2007). Approximately 2 weeks after virus injection, a custom head bolt was affixed to the skull with its posterior edge at lambda using dental acrylic, a cannula guide (\#C313G; Plastics One) was implanted through the nasal bone (position: $1 \mathrm{~mm}$ anterior of frontal/ nasal fissure and $1 \mathrm{~mm}$ lateral) into the dorsal recess $(0.5 \mathrm{~mm}$ depth) for subsequent monitoring of intranasal airflow, and a semichronic window for optical recordings was made by thinning the bone over the OB. All steps were performed in a single surgical procedure under ketamine/ medetomidine anesthesia. Aseptic techniques were used throughout the procedure and local anesthetic (bupivacaine, 1\%; Sigma-Aldrich) was applied to all incision areas. Mice received the same postsurgical treatment as for injections and were allowed to recover for $1 \mathrm{~d}$ before imaging.

Beginning 1-5 $\mathrm{d}$ after the surgical procedure, mice were acclimated to the head-fixed imaging apparatus, which consisted of a crossbar with custom female recess for securing the head bolt and a small PVC tube surrounding the mouse. An odor delivery port was positioned $\sim 5 \mathrm{~mm}$ in front of the animal's snout, and a lick spout made available for water delivery. The restraint setup was placed inside a box to limit external light and the imaging objective was extended through a port in the roof of the box. A fan at the rear of the animal removed odorants after presentation. Respiration was measured as intranasal airflow via a thermocouple (emtss-010 g-12; Omega Engineering) inserted through the cannula. Thermocouple signals were amplified (100-1000×, DP-301 differential amplifier; Warner Instruments), low-pass-filtered at 50 or $100 \mathrm{~Hz}$, and digitized at $500 \mathrm{~Hz}$. Odorant presentation, olfactometer control, water delivery, and data acquisition triggers were controlled with software custom written in LabVIEW (National Instruments).

For calcium imaging from ORNs, wild-type albino B6 mice were first trained in a go/no-go two-odor discrimination task for which they received water reward (Verhagen et al., 2007). After successful training, mice were anesthetized with ketamine/medetomidine and their ORNs were loaded with Calcium Green-1 dextran or Oregon Green BAPTA-1 dextran (both $10 \mathrm{kDa}$ ) using established protocols (Wachowiak and Cohen, 2001) in a noninvasive procedure. Collection of imaging data began 3-7 d after loading and during performance of the discrimination task. For imaging from postsynaptic neurons, mice were simply placed in the restraint apparatus with no operant conditioning and persistent limb movement or severely attenuated respiration was used as an indicator of excessive stress. In all cases, a single imaging session lasted for up to 60 min and data were collected over as many as five consecutive daily sessions. To compare optical signals during wakefulness and anesthesia (Fig. 9), head-fixed mice were briefly anesthetized with isoflurane and their responses to odorants were imaged in the 1-2 min after anesthetic was removed.

Epifluorescence data analysis. Basic processing and analysis of optical signals followed protocols described previously for epifluorescence imaging from ORNs (Wachowiak and Cohen, 2001; Verhagen et al., 2007; Wesson et al., 2008; Carey et al., 2009). Initial data processing included, where applicable, subtraction of nonodor, "blank" trials to eliminate any photobleaching (this was minimal or nonexistent for GCaMP signals under most illumination conditions), extracting fluorescence time courses from visually selected regions of interest (ROIs), up-sampling of optical signals to $100 \mathrm{~Hz}$ to match the acquisition rate of respiratory signals, and offline correction of small movements in data from headfixed mice. In anesthetized preparations, 3-8 repeated trials were averaged before analysis. For display in the figures, odorant response maps were scaled from 0 to $95 \%$ of the maximal $\Delta F$ for that map and the pixel resolution was doubled (to $512 \times 512$ ) using bilinear interpolation; epifluorescence traces were smoothed with a low-pass Gaussian kernel with a cutoff of $6-8 \mathrm{~Hz}$.

Peak odorant-evoked response amplitudes were measured from ROIs consisting of 9-12 pixels centered on well defined signal foci (Verhagen et al., 2007) and computed as the average signal in 5 frames centered around the peak of the inhalation-evoked response, minus the 5 -frame average before odorant onset $(\Delta F)$, then divided by the resting fluorescence measured from the first 5 frames of the trial $(\Delta F / F)$. For response maps (Fig. 7), $\Delta F$ values were calculated from temporal averages of the 80 frames $(3.2 \mathrm{~s}$ ) before odorant onset and 80 frames after the first inhalation of odorant for GCaMP signals, and of 20 frames before odorant onset and at the end of odorant presentation for $\mathrm{spH}$ signals. For autocorrelation analysis, these maps were demeaned and the resulting autocorrelations normalized to their peak amplitude. Autocorrelation widths were determined as the average diameter of a contour line drawn at $75 \%$ of the maximum value to generate glomerular widths that were consistent with previously reported values $(\sim 90 \mu \mathrm{m}$ for $\mathrm{spH}$ maps $)$ (Bozza et al., 2004). To generate consensus odorant response topographies (Fig. 5), response maps were interpolated to $512 \times 512$ pixels, smoothed with a $6 \times 6$ pixel $(52 \mu \mathrm{m})$ mean kernel, and aligned across preparations using the caudal sinus and midline of the dorsal bulbar region (Bozza et al., 2004), after which each map was thresholded at $40 \%$ maximal amplitude, further smoothed (Gaussian kernel with an SD of 12 pixels), normalized in amplitude, and responses to the same odorant averaged across preparations.

For analysis of anesthesia effects (Fig. 9), peak response amplitudes from 1-6 strongly activated foci were measured in each preparation. Measurement of signal onset latencies and rise times relative to inhalation were made as described previously for rat optical signals using a custom algorithm that fit the optical signals to a double sigmoid function (Wesson et al., 2008). The algorithm was modified slightly to fit the higher sniffing frequencies in awake mice. Onset time was defined as the time the fitted optical signal reached $10 \%$ of its maximal amplitude (t10); rise-time was defined as the time from $10-90 \%$ of maximal amplitude. Response onset latencies in awake mice were measured relative to the start of the first inhalation after odorant onset as reported by an upward deflection in the thermocouple signal. For descriptive statistics, latencies and rise times were measured from multiple foci and multiple odorants and averaged across inhalations of odorant in one session before computing a grand average across animals. For comparison of anteromedial versus caudal-lateral dynamics, latencies and rise times were measured for the first inhalation of odorant and measurements were made for 3-4 
ROIs in each domain and then averaged to obtain a single latency and rise time value per domain per preparation. Relative values between the domains in each preparation were plotted and compared using a paired $t$ test (Fig. 6). All analyses were performed using software custom written in MATLAB or LabVIEW. All statistical tests were performed with MATLAB or Origin and were two-sided, unpaired $t$ tests unless stated otherwise. Summary data are reported as mean \pm SD unless noted otherwise.

Histology and immunohistochemistry. Mice were deeply anesthetized with an overdose of sodium pentobarbital and perfused with PBS followed by $4 \%$ paraformaldehyde in PBS. Heads were postfixed overnight at $4^{\circ} \mathrm{C}$ before brains were extracted and stored in PBS until they were processed further. For histological controls, brains were embedded in 5\% agarose and $200 \mu \mathrm{m}$ coronal sections in coronal orientation were obtained with a Vibratome. For immunohistochemistry, brains were cryoprotected in 30\% sucrose in PBS. OBs were embedded in optimal cutting temperature compound (Tissue-Tek OCT Compound; Sakura-Fintek) and coronal slices $(15-30 \mu \mathrm{m})$ were cut on a cryostat. Slices were first rinsed with PBS and nonspecific binding was blocked with 5\% normal goat serum diluted in PBS with $0.1 \%$ Triton X-100 for $1 \mathrm{~h}$ at room temperature before incubation with primary antibody (rabbit antiTbx21,1:1000; kindly provided by Y. Yoshihara, RIKEN) or rabbit anti-TH (Bioscience Research Reagents\#AB152, 1:500; Millipore) in PBS with $0.01 \%$ Triton-X overnight at $4^{\circ} \mathrm{C}$. The primary antibody was detected with an Alexa Fluor 543-conjugated goat anti-rabbit secondary antibody (A-11010, 1:1000; Invitrogen) incubated for $1 \mathrm{~h}$ at room temperature. Intrinsic GCaMP expression was enhanced in cryosections of reporter animals by counterstaining with a FITC-conjugated GFP antibody (\#ab6662, 1:150; Abcam) for $4 \mathrm{~h}$ at room temperature. Sections were analyzed with an Olympus IX70 FV1000 or FV10i confocal laser scanning inverted microscope at $10 \times, 20 \times$, or $60 \times$ magnification. Colocalization of protein markers and the distribution of labeled cells in different OB layers was quantified by manually counting cells from confocal stacks taken from 3-5 representative sections of the dorsal $O B$ in each animal.

\section{Results}

\section{Expression of GCaMP3 and GCaMP5G in defined OB neuron subpopulations}

We used mouse lines expressing Cre recombinase in genetically defined neuronal populations to achieve selective expression of genetically encoded calcium indicators in three major classes of OB neurons. GAD2-Cre mice (Taniguchi et al., 2011) were used to drive expression in GABAergic interneurons expressing the 65 $\mathrm{kDa}$ variant of glutamic acid decarboxylase (GAD65). The GAD $65{ }^{+}$chemotype comprises $\sim 60 \%$ of granule cells and $40 \%$ of all juxtaglomerular interneurons (Parrish-Aungst et al., 2007). Among the juxtaglomerular interneurons, nearly all GAD65 ${ }^{+}$ neurons have processes that branch extensively within a single glomerulus and so fit the classical definition of PG cells (Kiyokage et al., 2010). TH-Cre mice were used to drive expression in a second, morphologically distinct class of juxtaglomerular interneurons that coexpress, along with $\mathrm{TH}$, the $67 \mathrm{kDa} \mathrm{GAD}$ isoform (Kosaka and Kosaka, 2008; Kiyokage et al., 2010). $\mathrm{TH}^{+} /$ $\mathrm{GAD}^{+} 7^{+}$interneurons innervate multiple glomeruli, are the primary source of interglomerular connections in the $\mathrm{OB}$, and fit the classical description of SA cells (Kosaka and Kosaka, 2008; Kiyokage et al., 2010). Finally, PCdh21-Cre mice were used to drive expression in MT cells, which represent the primary output stream from the OB (Shipley and Adamek, 1984; Nagai et al., 2005; Mitsui et al., 2011) (Kato et al., 2012). The PCdh21 protein is a member of the nonclassical cadherins that is expressed strongly in the $\mathrm{OB}$ and weakly, if at all, elsewhere in the forebrain (Nagai et al., 2005).

Two variants of the circularly permuted calcium sensor GCaMP, GCaMP3 (Tian et al., 2009) and GCaMP5G (Akerboom et al., 2012), were expressed using either a Cre-dependent viral vector (Atasoy et al., 2008) or by crossing with the Cre-dependent GCaMP3 reporter line Ai38 (Zariwala et al., 2012). We first characterized the expression and basic functional properties of the GCaMP transgenes using both expression modalities, because the two methods can result in different levels of expression and, potentially, different distributions across cell types due to effects of viral serotype and developmental sequences of Cre expression. Figure 1 shows the expression of GCaMP3 in reporter crosses and after virus injection into the $\mathrm{OB}$ for GAD2-Cre (Fig. $1 A$ ), TH-Cre (Fig. 1B), and PCdh21-Cre mice (Fig. 1C). Viral expression patterns were variable in spatial extent, depth, and density and included a subset of the neurons expressing GCaMP3 in reporter crosses. In GAD2-Cre mice, expression in reporter crosses appeared stronger in granule cells than in PG cells, although PG cells were still apparent in fixed sections (Fig. $1 A$ ) and in vivo (see below). Expression in TH-Cre reporter crosses included, in addition to numerous juxtaglomerular neurons, smaller numbers of neurons with somata in the outer external plexiform layer (EPL; $\sim 10 \%$ of juxtaglomerular cell number, 211 vs 1741 cells, 3 mice) and deep EPL/superficial granule cell layers ( $\sim 15 \%$ of juxtaglomerular cell number, 290 vs 1741 cells) and in the accessory OB (data not shown), whereas virus injection led to expression almost exclusively in juxtaglomerular neurons (Fig. $1 B$ ).

In PCdh21-Cre mice, reporter-driven expression of GCaMP3 or tdTomato (using the Ai9 reporter line) led to expression in MT cells and clear expression in ORNs (Fig. 1C). In both the Ai38 and Ai9 lines, expression appeared strongest in neurons with somata in the superficial EPL (presumed tufted cells), leading to the brightest fluorescence in their lateral dendrites just beneath the glomerular layer, along with a sparse unidentified population of neurons with small somata in the deep EPL (Fig. 1C). Virusdriven expression of GCaMP3 was absent in ORNs and deep EPL neurons. We observed no expression in the granule cell layer.

The PCdh21 promoter also likely drives expression in glutamatergic neurons that remain intrinsic to the $\mathrm{OB}$, such as external tufted and some superficial tufted cells (Shipley et al., 2004; Schoenfeld et al., 1985; Hayar et al., 2004; Nagai et al., 2005; Mitsui et al., 2011). Therefore, we used an anatomical approach to ensure GCaMP expression solely in PCdh21 + OB output neurons. To achieve this, virus was injected into aPC, leading to robust and widespread expression of GCaMP in mitral cells and a minority of tufted cells throughout the $\mathrm{OB}$, with no expression in somata in aPC (Fig. 1D). This retrograde infection approach allowed us to exclude potential contributions of intrinsic PCdh21 + cell types and to image activity selectively from OB neurons projecting to cortex.

We further assayed cell-type specificity of expression by immunostaining for TH in GAD2-Cre and TH-Cre:GCaMP3 reporter mice and for the MT-cell-specific marker Tbx21 (Nagai et al., 2005; Mitsui et al., 2011) in GAD2-Cre and TH-Cre:GCaMP3 reporter mice and in PCdh21-Cre mice expressing GCaMPs after retrograde viral infection. In GAD2-Cre and $\mathrm{TH}-\mathrm{Cre}$ reporter crosses, GCaMP3-expressing juxtaglomerular neurons were Tbx21 ${ }^{-}$(GAD2-Cre: $4 / 508$ cells, $n=3$ mice; TH-Cre: $0 / 405$ cells, $n=3$ mice; Fig. $2 A, B)$. In GAD2-Cre:GCaMP3 reporter mice stained for $\mathrm{TH}$, a minority (14\%) of juxtaglomerular neurons showed colabeling (91/627 cells, $n=3$ mice; Fig. $2 C)$, which is consistent with previous estimates of a small overlap between GAD65 and TH-expressing neurons (Kiyokage et al., 2010). In TH-Cre:GCaMP3 reporter crosses, 90\% of GCaMP3-expressing neurons in the glomerular layer showed TH immunoreactivity (228/256 cells, $n=3$ mice; Fig. $2 D)$, whereas those in the EPL 
A GAD2 reporter

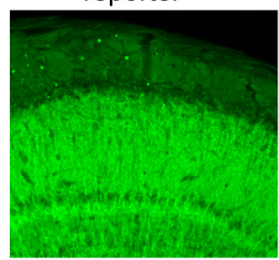

GL
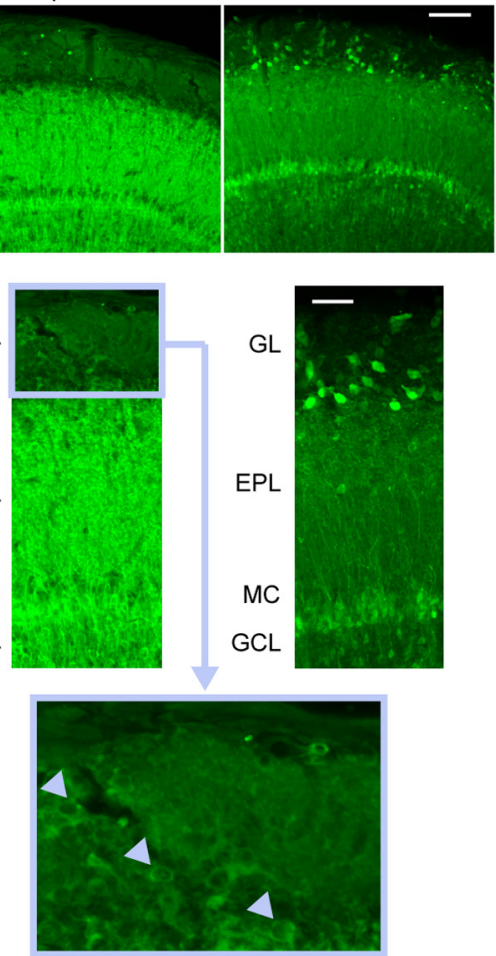

B TH
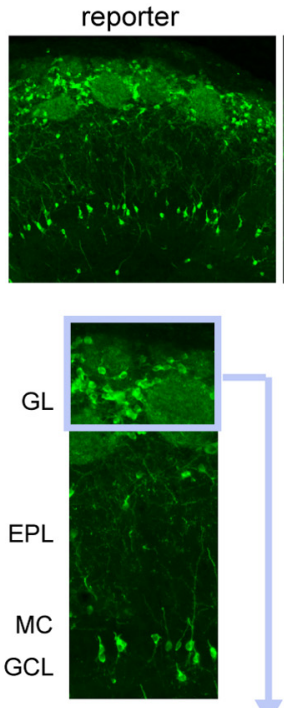

GL

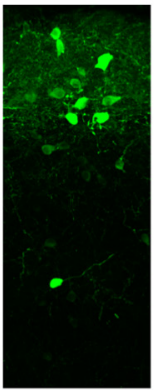

GCL

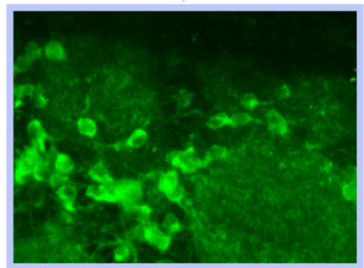

C PCdh21

reporter (Ai9)
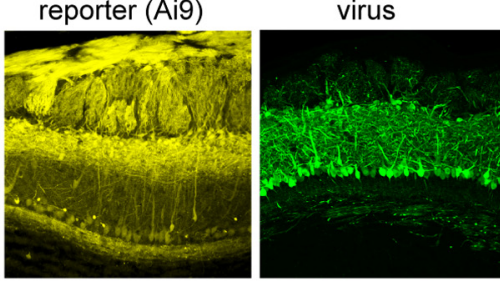

GL

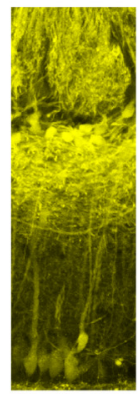

GL
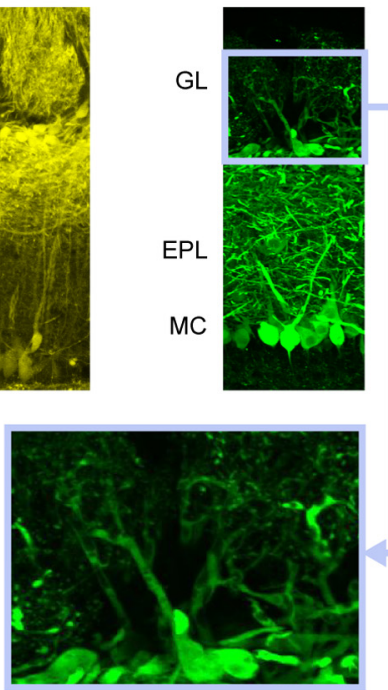

D PCdh21, aPC injected
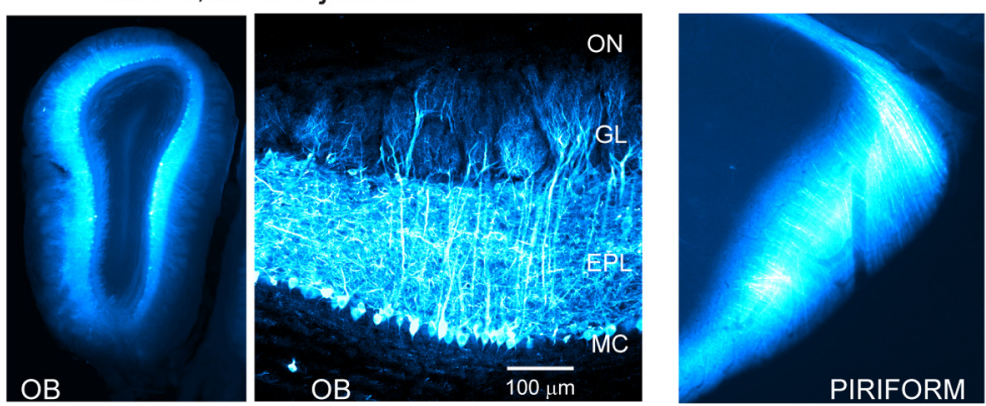

Figure 1. Cre-dependent transgene expression in $\mathrm{GAD}^{+}{ }^{+} \mathrm{TH}^{+}$, and $\mathrm{PCdh} 21^{+}$neurons in the $\mathrm{OB} . \boldsymbol{A}-\boldsymbol{C}$, Labeling of OB neurons after crossing Cre driver lines with a reporter mouse line (left, "reporter") or after injection of Cre-dependent virus into the OB (right, "virus") for GAD2-Cre (A), TH-Cre (B), and PCdh21-Cre ( $\boldsymbol{C}$ mice. Top panels are overview images (bar, $100 \mu \mathrm{m}$ ), middle panels show higher-magnification images in different $\mathrm{OB}$ layers (bar, $50 \mu \mathrm{m}$ ), and bottom panels show magnified images of the glomerular layer of reporter-driven $(\boldsymbol{A}, \boldsymbol{B})$ or virus-driven $(\boldsymbol{C}) \mathrm{GCaMP}$ expression. Reporter lines are GCaMP3 (Ai38) for GAD2-Cre and TH-Cre and tdTomato (Ai9) for PCdh21-Cre. GL indicates glomerular layer; MC, mitral cell layer. Note that the expression in GAD2-Cre:reporter crosses ( $\boldsymbol{A}$ ) appeared brighter in granule cells but was still evident in PG cells (arrowheads). Expression in TH-Cre:reporter crosses included sparsely distributed neurons in the EPL and superficial granule cell layer (B), and expression in PCdh21-Cre:GCaMP3 reporter crosses included ORNs (C); these neurons did not show expression after virus injection. $\boldsymbol{D}$, Expression of GCaMP after injection of Cre-dependent viral vector into the aPC of a PCdh21-Cre mouse (pseudocoloring in cyan to distinguish retrograde expression from direct expression in C). Expression is widespread throughout the $\mathrm{OB}$ (left) and occurs preferentially in mitral and deep tufted cells and their dendrites throughout the EPL (middle). Right: Axon terminals of GCaMP-expressing MT cells in piriform cortex. Note the lack of GCaMP-expressing somata in piriform.

were $\mathrm{TH}^{-}$(7/181 were $\mathrm{TH}^{+}$cells). Finally, in PCdh21-Cre mice expressing GCaMP after retrograde infection, $~ 95 \%$ of GCaMPexpressing neurons were positive for Tbx21 (214/225 cells, $n=3$ mice; Fig. 2E). Therefore, GAD2-Cre, TH-Cre, and PCdh21-Cre mice allow for selective expression of GCaMPs or other transgenes in distinct and largely nonoverlapping populations of $\mathrm{OB}$ neurons.

Characterization of GCaMPs as reporters of neural activity Before imaging $\mathrm{OB}$ activity in vivo, we first characterized the relationship between neural activity and GCaMP fluorescence in vitro using simultaneous whole-cell or cell-attached recordings and two-photon $\mathrm{Ca}^{2+}$ imaging in acute slices of the OB (Fig. $3 A i)$. Alternatively, we used piriform cortex slices in which GCaMP5G was expressed using a Cre-independent vector as a comparison (for details, see Fig. 3 legend). As expected, peak GCaMP fluorescence increased when increasing numbers of spikes were evoked by square current steps (Fig. 3Aii,Aiii). For GCaMP5G- and GCaMP3-expressing neurons, the mean decay time constant after a spike burst was $1.19 \pm 0.73 \mathrm{~s}(n=8)$. The threshold number of action potentials required to evoke a suprathreshold GCaMP signal ( $>4$ SDs above zero) was lower for GCaMP5G-expressing MT cells compared with GCaMP5Gexpressing piriform cortex neurons and reporter-driven 
A
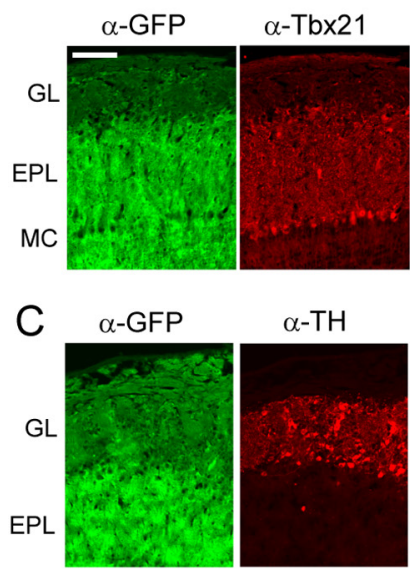

$\alpha-\mathrm{TH}$

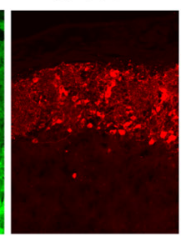

overlay

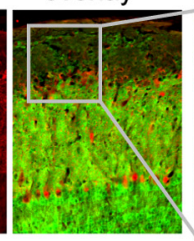

overlay

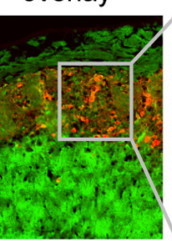

B
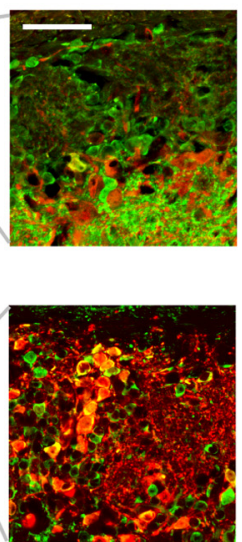

TH-Cre:GCaMP3 reporter
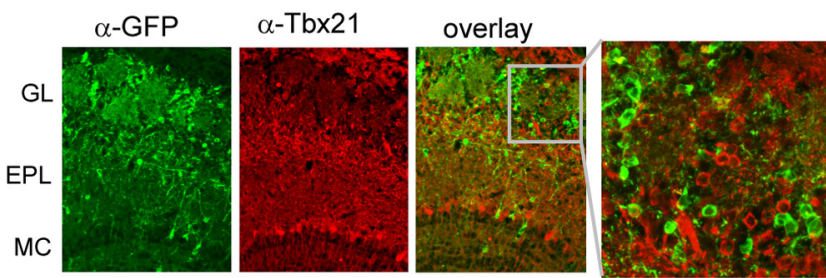

$\mathrm{D}$
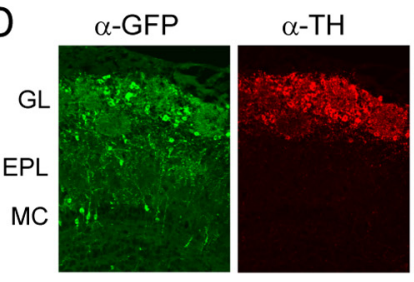

overlay

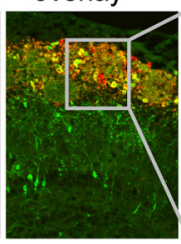

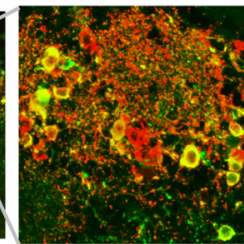

E PCdh21-Cre, GCaMP3 AAV aPC injected

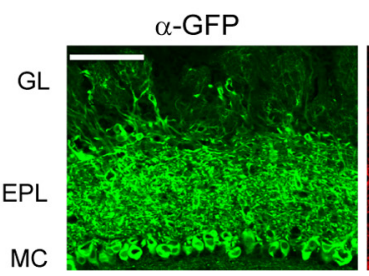

$\alpha-\operatorname{Tbx} 21$

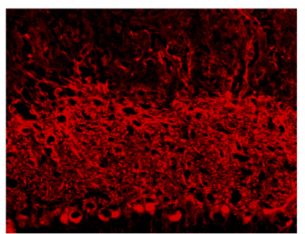

overlay

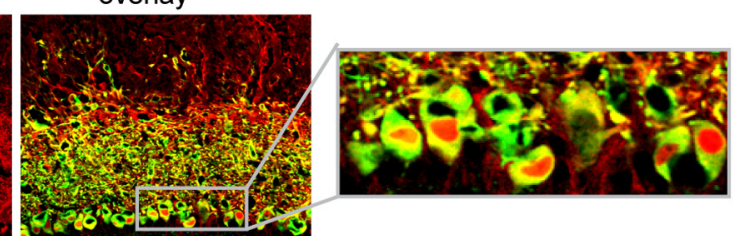

Figure 2. Immunohistochemical verification of cell-type-selective expression in OB neurons. $A-E$, Immunohistochemical staining of OB sections of GAD2-Cre:GCaMP3 reporter mice $(A, C)$, TH-Cre:GCaMP3 reporter mice $(\boldsymbol{B}, \boldsymbol{D})$, and (drh1-Cre mice injected with GCaMP3-expressing virus into aPC (E). Images in $\boldsymbol{A}-\boldsymbol{D}$ show anti-GFP enhanced GCaMP expression (green, left), immunostaining for Tbx21 $(A, B, E)$, or TH (C,D) (red, middle) and an overlay of both channels including a magnified section of the glomerular layer (right). Bars indicate 100 and $50 \mu \mathrm{m}$ for full and magnified views, respectively. Tbx21 antibody labels mitral and tufted cells but not $\mathrm{GAD}^{+}{ }^{+}$or $\mathrm{TH}^{+}{ }^{+}$neurons expressing GCaMP $(\boldsymbol{A}, \boldsymbol{B})$. TH antibody labels only a minority of GCaMP-expressing juxtaglomerular neurons in GAD2-Cre:GCaMP3 reporter crosses (C), but labels most such neurons in TH-Cre:GCaMP3 reporter crosses (D). TH-Cre:GCaMP3 reporter crosses also show GCaMP3 expression in sparsely distributed infraglomerular neurons not labeled by TH antibody.

GCaMP3-expressing MT cells, with a minimum of $\sim 6$ action potentials during a $500 \mathrm{~ms}$ current step (Fig. 3Aiv). In general, however, spike detection threshold depended upon the number of spikes, spike frequency, and whether spike bursts were superimposed on periods of low-frequency spontaneous spiking.

We next established a general relationship between GCaMP fluorescence and changes in spike rate using three parameters: two time constants, $\tau_{\text {on }}$ and $\tau_{\text {off }}$, accounting for the kinetics of increase and decrease in fluorescence after an action potential, and an exponent $a$ to account for observed nonlinearities in the relationship between spike number and fluorescence change (Akerboom et al., 2012). Optimization of these three parameters (see Materials and Methods) allowed us to obtain excellent fits between filtered spike rates and GCaMP fluorescence changes $(\Delta F)$ both for step-evoked spike bursts (analogous to the inhalation-evoked bursts that often occur in $\mathrm{OB}$ neurons in vivo) and for periods of irregular spiking (Fig. 3B). Across recorded mitral cells $(n=8)$ in which GCaMP3 or GCaMP5G was virally expressed, the mean correlation coefficient $\left(r^{2}\right)$ between $\Delta F$ and spike rate after convolution of spike times with the derived time constants and linearization of the fluorescence using the derived exponent was $0.93 \pm 0.02$. The optimal rise and decay time constants for the GCaMP signal were $0.11 \pm 0.05$ and $3.09 \pm 1.26 \mathrm{~s}$, respectively (ranges, $\tau_{\text {on }}: 0.0012-0.18 \mathrm{~s} ; \tau_{\text {off }}: 1.53-5.24 \mathrm{~s}$ ). The mean value of exponent $a$ in these cells was $1.62 \pm 0.28$ (range, $1.18-1.91$ ), suggesting a supralinear relationship between spike rate and $\Delta F$, which is consistent with a recent characterization of a related GCaMP5 variant (Akerboom et al., 2012) but different from recent characterizations of GCaMP3 (Tian et al., 2009; Borghuis et al., 2011).

The apparent supralinear nature of the spike rate-fluorescence relationship might arise from a thresholding effect in which $\Delta F$ decreases to zero at some nonzero spike rate and the resulting discontinuity is blurred by noise or spatial averaging to yield a concave curve. To test this possibility, we also derived the optimal time constants and exponent from the same time-varying spike trains but using only epochs in which the measured spike rate was $>40 \%$ of the maximal value, a region that should be unaffected by threshold effects. These fits led to exponents not significantly different from unity $(0.95 \pm 0.18 ; p=0.38$, one-sample $t$ test $)$. Therefore, threshold effects during periods of infrequent spiking constitute one explanation for the apparent supralinear relationship between spike rate and GCaMP fluorescence observed here and described previously (Akerboom et al., 2012). Finally, in both GCaMP3- and GCaMP5G-expressing MT cells, evidence of saturation was observed only rarely except when high spike rates were elicited for prolonged periods of time (Fig. 3C). In fact, in many cells, spiking failed and depolarization block was reached before fluorescence responses saturated (data not shown).

Spike rate/ $\Delta F$ fit parameters varied somewhat with expression modality and intracellular compartment. Neurons from GCaMP3-expressing reporter mice $(n=10)$ had modestly lower $\tau_{\text {off }}$ constants, which is consistent with lower expression levels and with previous reports (Zariwala et al., 2012; Fig. 3D), and the spike rate/ $\Delta F$ relationship appeared linear in these neurons, with an optimal exponent not significantly different from unity 


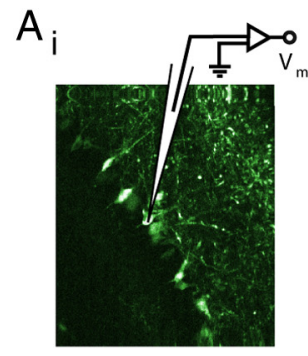

B
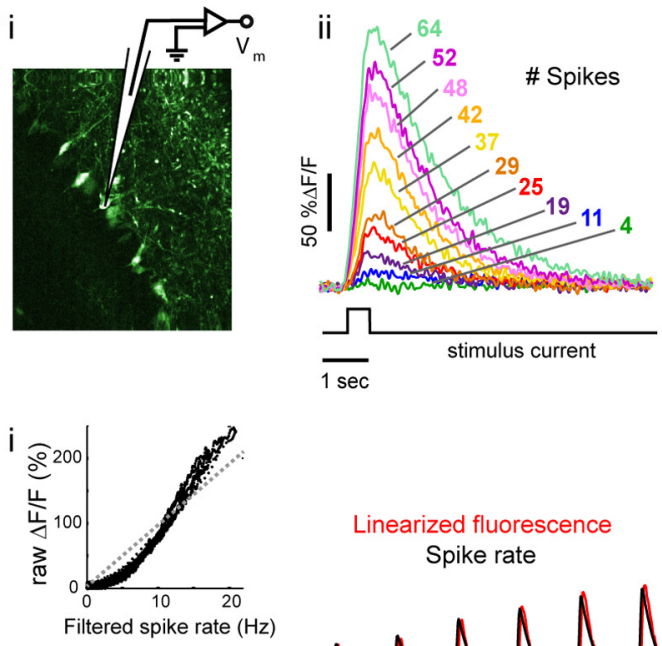

Linearized fluorescence Spike rate

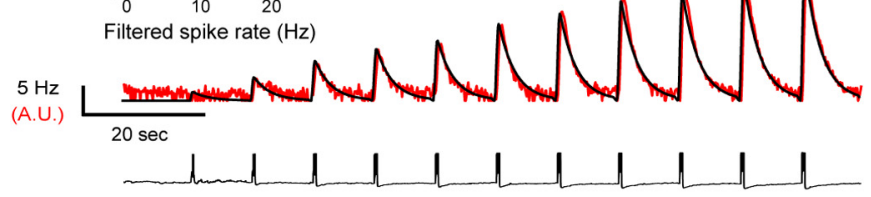

iii

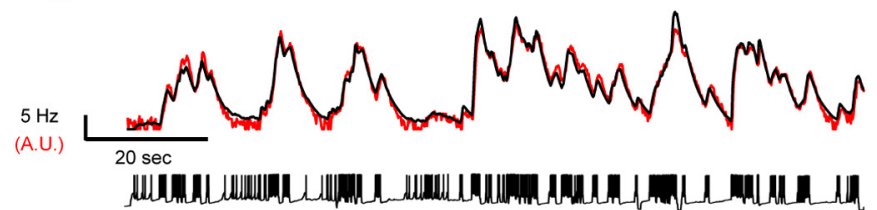

$\mathrm{C}_{\mathrm{i}}$
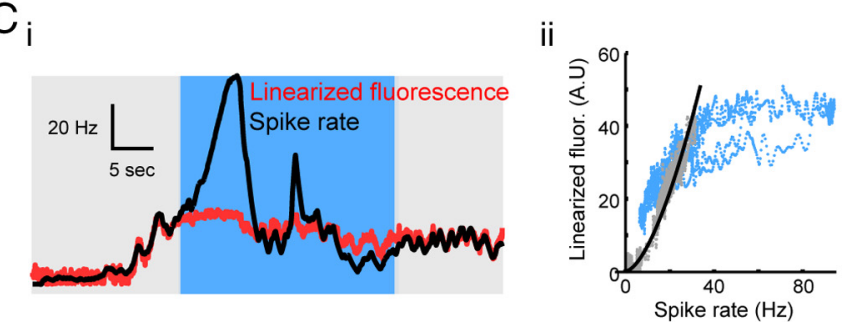

iii

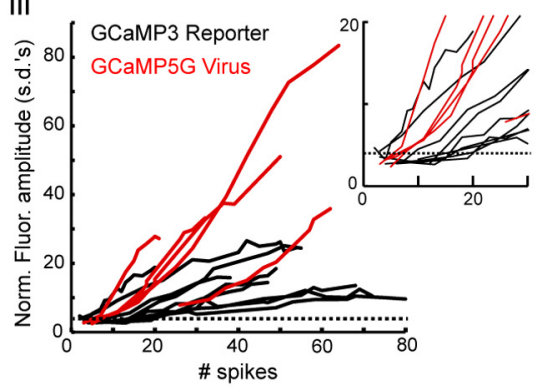

ii

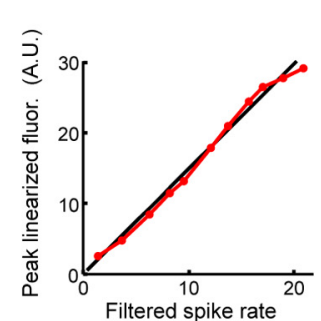

iv

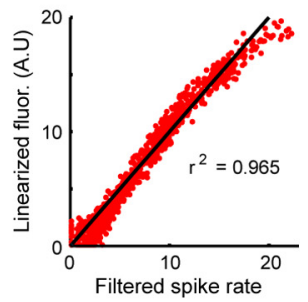

iv

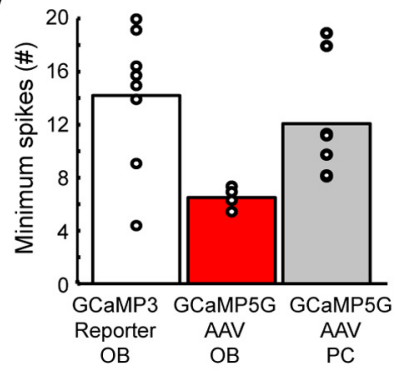

$\mathrm{D}$
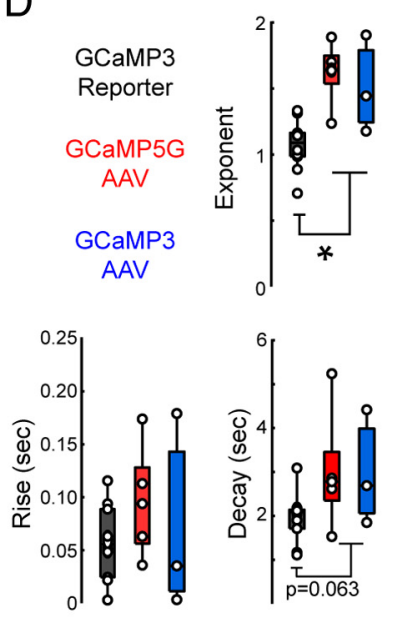

$E_{i}$

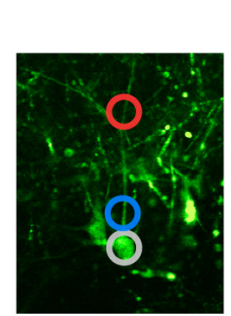

ii Soma

Proximal dendrite Distal dendrite

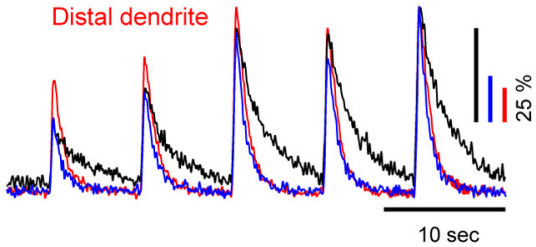

Figure 3. Deriving quantitative relationships between action potential firing and GCaMP signals. Ai, In vitro whole-cell recordings were made from putative MT neurons expressing either GCaMP3 or GCaMP5G. Aii, Fluorescence transients corresponding to spike bursts elicited by square current steps in a GCaMP5G expressing MT neuron. Numbers indicate number of spikes evoked by each step. Aiii, Peak fluorescence amplitude in response to increasing numbers of spikes during a $500 \mathrm{~ms}$ current step. Dotted line in Aiii indicates the approximate threshold for detectable spike-related fluorescence transients. Inset is a magnification of the region around the threshold. Aiv, Minimum number of spikes occurring during the $500 \mathrm{~ms}$ window to elicit a detectable fluorescence response. The threshold for detecting spiking activity was lower when GCaMP5G was virally expressed in MT cells $(6.2 \pm 0.8 ; n=5)$ than in piriform neurons $(12.1 \pm 3.8$ spikes; $n=8)$ or in MT cells expressing reporter-driven GCaMP3 (14.2 \pm 4.9 spikes; $n=8)$. Bi, Linearized fluorescence trace (red) and spike rate (black) calculated by optimizing the time constants $\tau_{\text {on }}$ and $\tau_{\text {off }}$ and the exponent $a$ for the nonlinear fit during spike bursts (see text for details). Inset illustrates supralinear relationship between raw fluorescence and spike rate. Bii, Peak linearized fluorescence (adjusted after exponent derivation) increased approximately linearly in response to successively larger spike bursts. Biii, Linearized fluorescence waveform (red) and time-averaged spike rate (black) during irregular spiking (raw voltage trace is shown at bottom). Biv, Scatterplot of all linearized fluorescence values and corresponding spike rates for this entire trial. Ci, Linearized fluorescence (red) and spike rate (black) during a period of sustained high-frequency spiking resulting in saturation of the indicator (timing indicated by cyan shading). Cii, Scatterplot of fluorescence values as a function spike rate showing that the relationship between these quantities is disrupted for a period of time after saturation (indicated by cyan shaded region and points). D, Box plots comparing time constants $\tau_{\text {on }}$ ("Rise") and $\tau_{\text {off }}$ ("Decay") and the nonlinearity exponent $a$ obtained for all cells (open circles) expressing GCaMP3 or GCaMP5G via virus or GCaMP3 reporter. The exponent was significantly lower for GCaMP3 reporter-expressing MT cells (asterisk). Ei, Simultaneous recordings of GCaMP5G fluorescence at the soma and two dendritic locations (circles) in a putative MT neuron. Spike bursts elicited by current injection at the soma elicit fluorescence transients that decay faster in dendritic compartments, even for locations adjacent to the soma (Eii).

$(1.07 \pm 0.18, p=0.26)$. We also found that GCaMP dynamics were faster when imaged from the dendritic versus the somatic compartment of the same neuron, with dendritic $\tau_{\text {on }}$ and $\tau_{\text {off }}$ reduced by $85.1 \pm 12.1 \%$ and $44.0 \pm 13.3 \%$, respectively $(p<0.05$, paired $t$ test, $n=4$ ) from values derived from GCaMP signals imaged simultaneously from the soma (Fig. 3E).

Because spike rate $/ \Delta F$ fit parameters are unknown for each cell during a typical imaging experiment, we also estimated the accuracy with which spike rate changes can be inferred from $\Delta F$ measurements using mean values for parameters derived from paired imaging and spike recordings. Applying the mean values reported above to all neurons, the mean correlation coefficient between linearized fluorescence and convolved spike rate was only modestly reduced, to $0.86 \pm 0.07$. The mean error in estimating the spike rate change after a current step was similar for optimally derived parameters versus mean parameters $(0.14 \pm$ 0.09 vs $0.13 \pm 0.07$, respectively). Overall, this analysis indicates that, with appropriate initial characterization, $\tau_{\text {on }}$ and $\tau_{\text {off }}$ values, 
A PCdh21
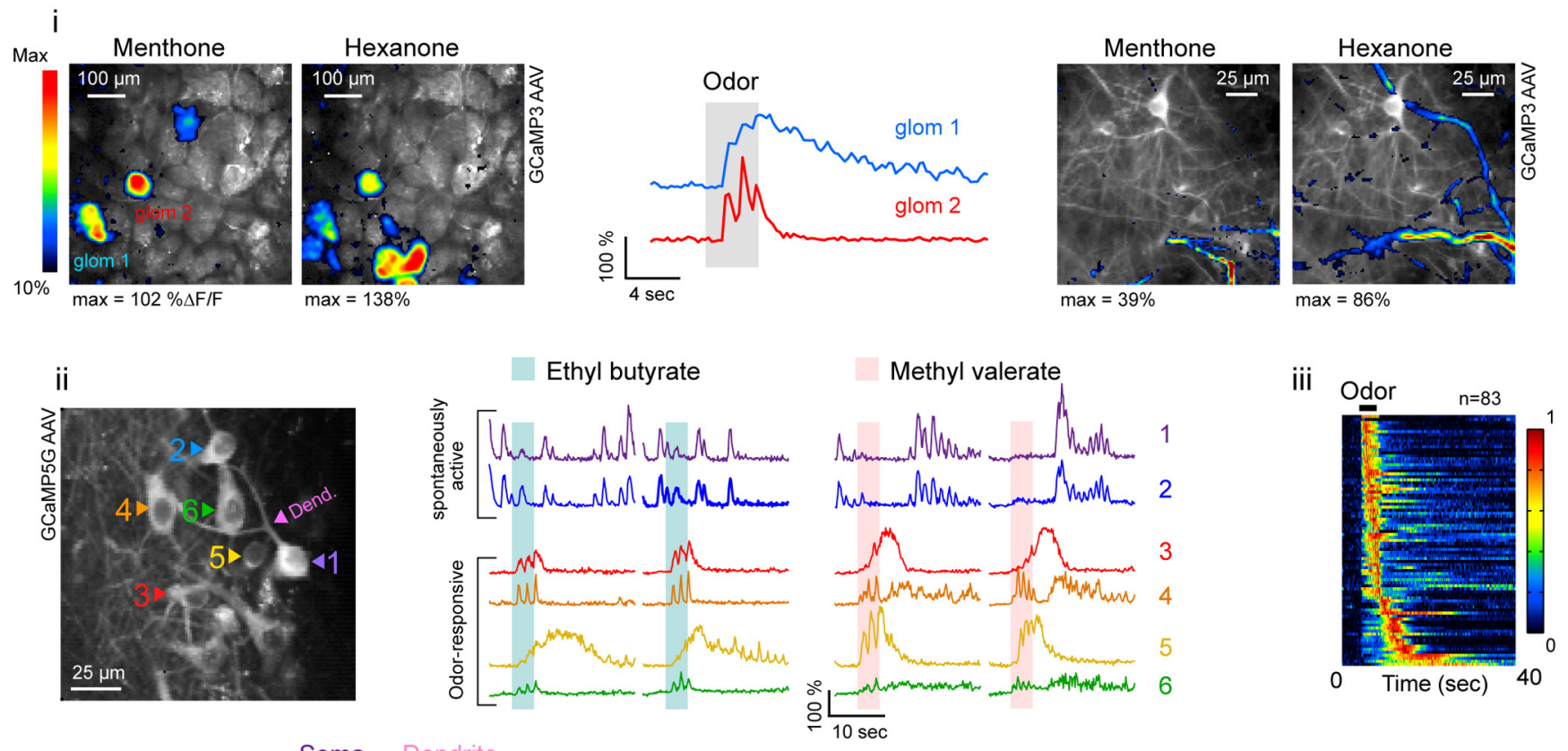

iv

Soma Dendrite

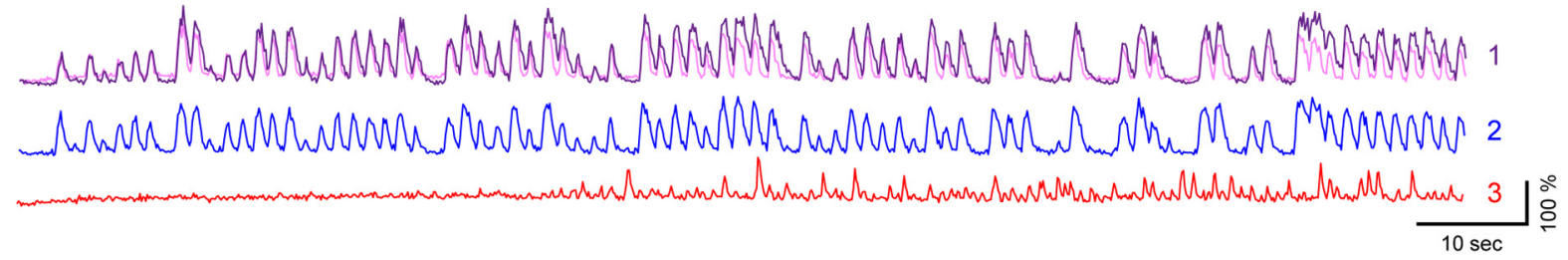

\section{B GAD2}
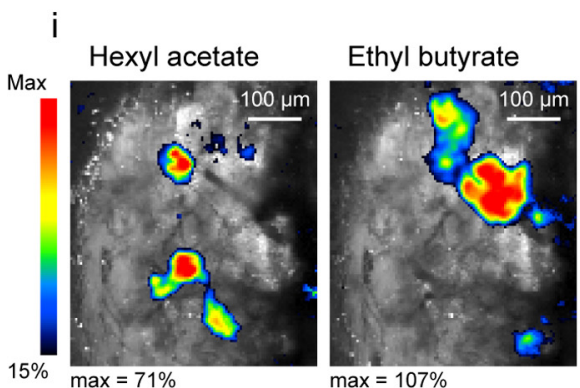

ii

\section{C $\mathrm{TH}$}

i

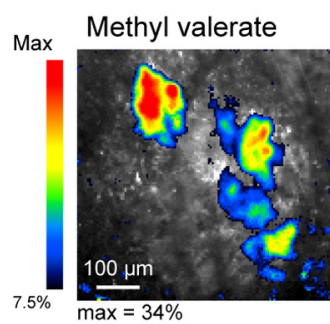

Ethyl butyrate

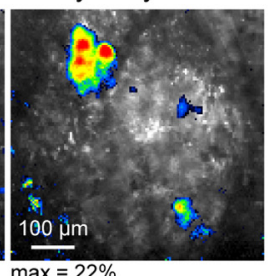

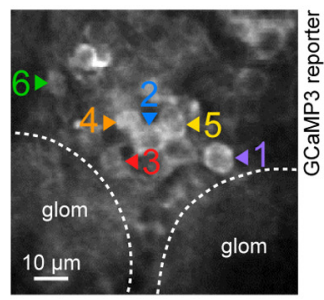

iii

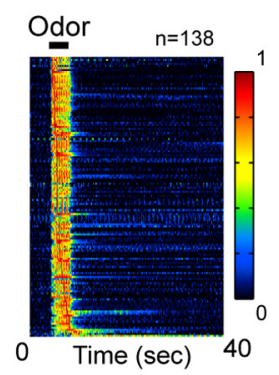

Figure 4. In vivo two-photon imaging of spontaneous and evoked activity in defined OB neurons. A, GCaMP signals imaged in vivo with two-photon microscopy after retrograde virus infection in PCdh21-Cre mice. Ai, Left: Resting fluorescence and pseudocolor overlay of odorant-evoked fluorescence change in the glomerular layer. Odorant stimulation evoked GCaMP signals restricted to a subset of glomeruli, the borders of which were demarcated by the tufts of MT cell primary dendrites. Middle: Time course of GCaMP fluorescence in two glomeruli from left image. Transients in lower trace are coupled to inhalation (timing not shown). Right: Resting fluorescence and pseudocolor overlay of evoked GCaMP signals in the external plexiform layer, showing odorant-specific activation of lateral dendritic processes. Aii, GCaMP signals imaged from mitral cell somata. Traces show GCaMP fluorescence imaged simultaneously from six mitral cells in one field of view. Neurons 1 and 2 did not respond to the two odorants tested, but showed coherent spontaneous signals; neurons 3- 6 each responded to both odorants but with distinct, reproducible dynamics. Aiii, Pseudocolor plot of mitral cell-odorant-evoked GCaMP signals in 83 cell-odorant pairs (one pair per row, imaged from the soma) showing considerable heterogeneity in temporal dynamics relative to the timing of odorant presentation (each row is the average of four trials normalized to peak response and ordered by latency to peak. Aiv, Spontaneous GCaMP signals in neurons (Figure legend continues.) 
along with a nonlinearity exponent derived from a subset of paired recordings, can be used to estimate firing rate changes from a different subset of imaged neurons with reasonable accuracy over a wide dynamic range.

\section{Two-photon imaging of spontaneous and evoked activity in identified neurons in vivo}

We next evaluated the utility of GCaMPs as reporters of spontaneous and odorant-evoked activity in these three OB neuron populations in vivo. In all mouse lines, virus-driven expression of GCaMP3 led to brighter resting fluorescence than virus-driven GCaMP5G or GCaMP3 reporter crosses, which is consistent with the lower basal fluorescence of GCaMP5G (Akerboom et al., 2012) and the lower expression levels of the GCaMP3 reporter (Zariwala et al., 2012). Many neurons expressing GCaMP5G were only transiently visible during periods of elevated activity due the lower basal fluorescence level.

Spontaneous and odorant-evoked fluorescence signals were apparent in the apical tuft, lateral dendrites, and somata of PCdh $21^{+}$MT cells. In the glomerular layer, odorant-evoked GCaMP signals were confined to distinct, odorant-specific combinations of glomeruli and could show distinct temporal dynamics across glomeruli (Fig. 4Ai). In the mitral cell layer, spontaneous transients, presumably reflecting spike bursts, were observed frequently; such transients were often highly correlated between a subset of somata in the same field of view (Fig. 4Aii), which is consistent with the idea that "sister" MT cells innervating the same glomerulus are electrically coupled and synchronously active (Schoppa and Westbrook, 2001; Christie and Westbrook, 2006; Ma and Lowe, 2010). Fitting the decay phase of spontaneous transients in MT cells led to decay time constants similar to those measured from MT cells in vitro after current step-evoked spike bursts $(0.95 \pm 0.24 \mathrm{~s}, n=6$ cells, $p=0.24)$. Also in agreement with the in vitro experiments, fluorescence transients decayed with faster kinetics in mitral cell dendrites than in somata (Fig. 4Aiv). Odorant-evoked GCaMP signals in mitral cell somata, like those in dendritic tufts, were often dominated by largeamplitude transients linked to inhalation, but across the population ( $n=83$ cell-odorant pairs, 8 mice) were temporally diverse and included increases occurring after odorant offset

\footnotetext{
(Figurelegend continued.) 1-3from Aii, including the signals from the soma (purple) and proximal apical dendrite (pink) of neuron 1 . Neurons 1 and 2 showed persistent spontaneous activity fluctuations that werenearly perfectly correlated. GCaMP fluorescencetransients decayed more quickly in the dendritic segments compared with the soma of neuron $1 . B, G C a M P$ signals imaged from the glomerular layer in GAD2-Cre:GCaMP3 reporter crosses. Bi, Resting fluorescence and pseudocolor overlay of odorant-evoked fluorescence change imaged at low magnification. Glomerular borders could not be identified from resting fluorescence images, but odorants evoked signals in odorant-specific foci resembling individual glomeruli. Bii, GCaMP fluorescence imaged at higher magnification and traces showing GCaMP signal imaged from six PG cell somata, all of which respond with similar dynamics to odorant presentation and show little or no spontaneous signals. Biii, Pseudocolor plot of odorantevoked GCaMP signals in $138 \mathrm{PG}$ cell-odorant pairs. In contrast to MT responses, $\mathrm{PG}$ cell responses were limited largely to the duration of odorant presentation. $C$, Resting and odorant-evoked GCaMP fluorescence imaged from the glomerular layer in TH-Cre:GCaMP3 reporter crosses. Ci, Resting and evoked GCaMP fluorescence imaged at low magnification, showing odorant-specific patterns of discrete signal foci resembling glomeruli. Cii, Higher-magnification resting fluorescence image and traces showing GCaMP signal from five SA cell somata in one field of view. The temporal dynamics of many cells within a given field of view tended to be similar, with little evidence of spontaneous activity. Ciii, Pseudocolor plot of odorant-evoked GCaMP signals in 97 SA cell-odorant pairs. Although all cells within a given field of view (demarcated by horizontal white lines) showed similar response dynamics, temporal patterns could vary across the population of imaged neurons. In a subset of these data (bottom), odorant presentation was $2 \mathrm{~s}$ instead of $4 \mathrm{~s}$. Long-duration odorant responses were observed even for these short stimuli.
}

(Fig. 4Aiii). Other temporal response patterns included slower ramps of activity and prolonged activity outlasting odorant presentation (Fig. 4Aii,Aiii). Odorant-evoked response patterns were specific for a soma-odorant pair and were consistent across trials. Therefore, GCaMPs expressed in PCdh21-Cre mice allow for the characterization of odorant specificity, response dynamics, and synchrony of activity across multiple individual $\mathrm{OB}$ output neurons.

In GAD2-Cre mice, presumptive PG cell somata in the glomerular layer were readily apparent after viral expression of GCaMP3 or GCaMP5G and were dim but discernible at high resolution in GCaMP3 reporter crosses (Fig. 4B). In TH-Cre: GCaMP3 reporter crosses, presumptive SA cell somata were easily identifiable in the glomerular layer (Fig. 4C). With GAD2-Cre and TH-Cre animals, individual glomeruli were not clearly distinguished from resting fluorescence at low magnification due to the presence of somata and interglomerular processes (Fig. $4 B, C)$. However, odorant presentation nonetheless resulted in focal activation of discrete regions confirmed to be single glomeruli at higher magnification (Fig. 4B,C). GCaMP-expressing somata of GAD2-Cre and TH-Cre mice rarely exhibited spontaneous fluorescence transients, but responded robustly and specifically to odorant presentation (Fig. $4 B, C$ ). In contrast to MT cell responses, however, PG cell response dynamics ( $n=138$ cell-odor pairs, 3 mice) were simple, consisting of a transient increase limited to the duration of odorant presentation (Fig. $4 B)$. GCaMP signals imaged from $\mathrm{TH}+\mathrm{SA}$ cell somata showed moderate temporal complexity, with all responsive cells $(n=97$ cell-odor pairs, four mice) increasing fluorescence upon odorant presentation, but with cell cohorts in some fields of view (presumably associated with the same glomerulus) showing responses far outlasting the stimulus (Fig. 4Ciii). Therefore, these two distinct juxtaglomerular interneuron populations show distinct properties of responsiveness to odorant stimulation.

\section{Topography of odorant representations among OB neuron subtypes}

We next characterized population-level patterns of odorantevoked activity among GAD2 ${ }^{+} \mathrm{PG}$ cells, $\mathrm{TH}^{+} \mathrm{SA}$ cells, and PCdh $21^{+}$MT cells using low-magnification epifluorescence imaging across the dorsal OB. Peak odorant-evoked GCaMP signals ranged from $10 \%$ to $185 \% \Delta F / F$ with epifluorescence; fluorescent changes were highest with GCaMP5G, which is consistent with the recent characterization of GCaMP5 variants (Akerboom et al., 2012). At the level of sensory input, odorants are represented as spatially organized patterns of input to OB glomeruli that have been well characterized using several presynaptic imaging methods (Wachowiak and Cohen, 2001; Bozza et al., 2004; Soucy et al., 2009; Ma et al., 2012). To visualize how these representations translate across different populations of $\mathrm{OB}$ neurons, we constructed spatial response maps of GCaMP signals evoked by a panel of odorants and compared these with patterns of ORN input using spH expressed in ORNs (Bozza et al., 2004; Fig. 5A). Response maps were imaged in GAD2-Cre and TH-Cre mouse lines using GCaMP3 reporter expression to avoid confounds of heterogeneous expression and potential tissue damage arising from local virus injection. Retrograde viral expression was used in PCdh21-Cre mice to selectively image activation of MT cells projecting to piriform cortex.

$\mathrm{SpH}$-derived response maps reflected ORN input to glomeruli located in distinct domains of the dorsal OB that matched those previously characterized for organic acids, ketones, esters, and amines (Bozza et al., 2004; Takahashi et al., 2004; Bozza et al., 
2009; Pacifico et al., 2012; Fig. 5A), and increasing odorant concentration recruited input to larger numbers of glomeruli and evoked larger-amplitude peak responses (Fig. 5A). Response maps imaged from GAD2-Cre mice and $\mathrm{TH}$-Cre mice also consisted primarily of discrete glomerular foci and only a minor diffuse signal and showed a similar concentration-dependent recruitment of glomerular number and response amplitude (Fig. 5A). Maps of PCdh $21^{+}$MT cells were noticeably more diffuse, with widespread GCaMP signals becoming more prominent at suprathreshold concentrations (Fig. 5A). In all three cell types, odorants evoked responses with similar topography across the dorsal $\mathrm{OB}$, with peak responses in domains that were highly overlapping for each odorant (Fig. 5B).

Spatially diffuse GCaMP signals may reflect the lateral spread of activity from the sites of glomerular ORN input. For example, the extensive interglomerular branching of $\mathrm{TH}^{+}$SA cells and the extensive lateral spread of MT lateral dendrites in the EPL are both hypothesized to mediate lateral inhibition within the $\mathrm{OB}$ (Yokoi et al., 1995; Aungst et al., 2003). Conversely, GAD2 ${ }^{+} \mathrm{PG}$ cells are largely uniglomerular. To compare the degree to which these cell types might transmit (or receive) excitatory inputs laterally, we measured the spatial contrast of epifluorescence GCaMP signals mapped across the dorsal OB for the same set of odorants tested in TH-Cre, GAD2-Cre, and PCdh21-Cre mice using autocorrelation analysis (see Materials and Methods). For comparison and to control for diffuse signals arising from scattered and out of focus light, we also analyzed $\mathrm{spH}$ response maps in which activated ORN axons remain confined to a single glomerulus. At low odorant concentrations that typically evoke input to only a few glomeruli for a given odorant, response maps from $\mathrm{GAD}_{2}{ }^{+}$and $\mathrm{TH}^{+} \mathrm{GCaMP}$ signals showed little evidence of lateral signal spread, with autocorrelation widths that were not significantly different from those of spH response maps (spH: $88.5 \pm 22.1 \mu \mathrm{m}, n=18$ maps, 9 bulbs; GAD2: $77.6 \pm 26.7 \mu \mathrm{m}, p=0.98, n=21$ maps, 5 bulbs; TH: $71.4 \pm$ $43.4 \mu \mathrm{m}, p=0.82, n=26$ maps, 9 bulbs; $p>0.8$ for both comparisons, one-way ANOVA and Tukey-Kramer honestly significant difference criterion). MT cell $\left(\mathrm{PCdh} 21^{+}\right)$-derived response maps were significantly more diffuse (177.3 $\pm 50.2, n=32$ mice, 11 bulbs, $p<$ 0.001 ). At suprathreshold concentrations of odorants that evoke stronger input to numerous glomeruli (e.g., ethyl butyrate; Fig. 5), autocorrelation widths were larger in all cases (GAD2: $112.7 \pm 43.2$ $\mu \mathrm{m}, n=15$ maps, 11 bulbs; TH: $125.5 \pm 25.5 \mu \mathrm{m}, n=7$ maps, 7 bulbs; PCdh21: $222.05 \pm 51.2 \mu \mathrm{m}, n=13$ maps, 13 bulbs), but, again, only MT cell $\left(\mathrm{PCdh} 21^{+}\right)$-derived response maps displayed significantly larger autocorrelation widths compared with those of spH response maps ( $n=18$ maps, 18 bulbs; for comparison between GAD2, TH, and Pcdh21 versus spH: $p=0.62, p=0.40$, and $p<$ 0.001 , respectively, one-way ANOVA). The most likely source of the
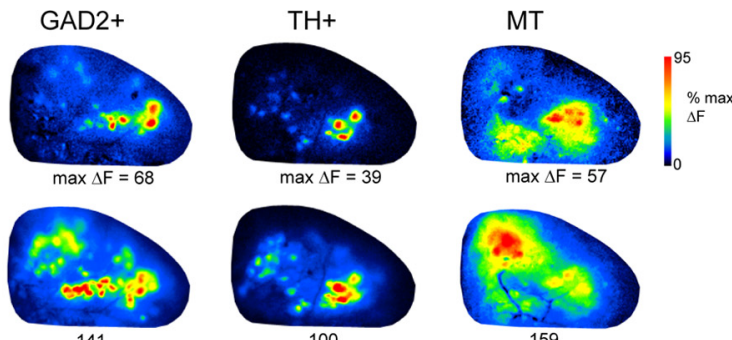

159

93

141
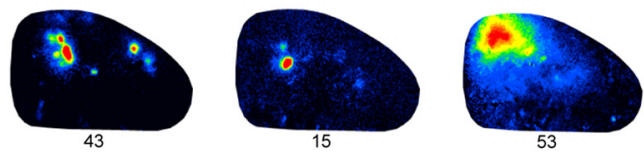

46
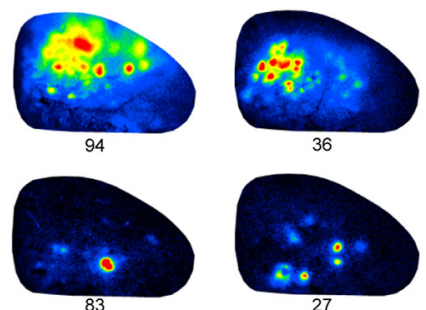

36
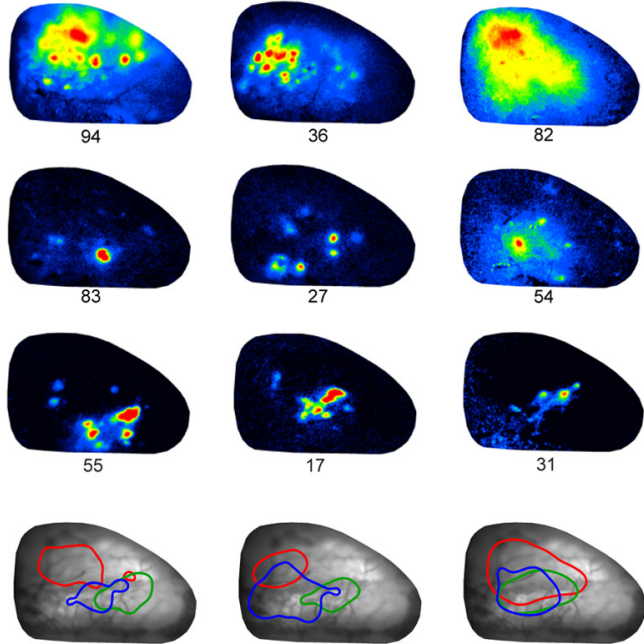

Figure 5. Odorant-evoked response maps imaged from different $0 \mathrm{~N}$ neuron types share similar topography. $\boldsymbol{A}, 0$ dorant-evoked response maps imaged in vivo from (left to right columns): ORNs (from OMP-spH mice), $\mathrm{GAD2}^{+}$neurons, $\mathrm{TH}^{+}$neurons, and PCdh21 ${ }^{+}$MT cells. All maps in the same column were imaged from the same animal, except when indicated by an asterisk.

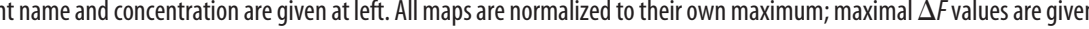
changes are not correlated with resting fluorescence (Bozza et al., 2004). In addition to similar topography, all response maps shared features including a recruitment of additional foci and an increase in peak amplitude with increasing odorant concentration. $\mathrm{SpH}, \mathrm{GAD}^{+}{ }^{+}$, and $\mathrm{TH}^{+}$maps consisted of discrete glomerular foci and a relatively small diffuse component. PCdh2 ${ }^{+}$MT maps had a more prominent diffuse component, especially at higher odorant concentrations. $\boldsymbol{B}$, Consensus topographies for response maps evoked by 2-hexanone (red), isopentylamine (blue), and butyric acid (green) overlaid on a reference bulb image. Lines indicate the $40 \%$ contour of response maps for each odorant averaged across multiple bulbs ( $n=5-8$ bulbs per cell type).

stronger diffuse GCaMP signals in PCdh21+ animals is action potential-mediated calcium influx into the lateral dendrites of tufted cells (Xiong and Chen, 2002; Debarbieux et al., 2003), which form an extensive network just below the glomerular layer (Fig. 1C, Fig. 3A). This conclusion is consistent with the observation that GCaMP signals mapped with two-photon imaging from the glomerular layer remained confined to discrete glomeruli (Fig. 4A).

\section{Inhalation-linked dynamics of odor representations across cell type}

Because odor information is also encoded in the temporal patterns of activity relative to respiration (Chaput, 1986; Spors et al., 2006; Cury and Uchida, 2010; Shusterman et al., 2011), we evaluated the degree to which GCaMPs can report respiration-linked dynamics among the different $\mathrm{OB}$ neuron populations and compared these dynamics against those reported by synthetic $\mathrm{Ca}^{2+}$ indicators loaded into ORNs (see Materials and Methods). Synthetic indicators loaded into ORN axon terminals can report differential onset dynamics for odorant-glomerulus pairs of $\sim 100$ ms (Spors et al., 2006; Fig. 6A). Inhalation-locked modulation 

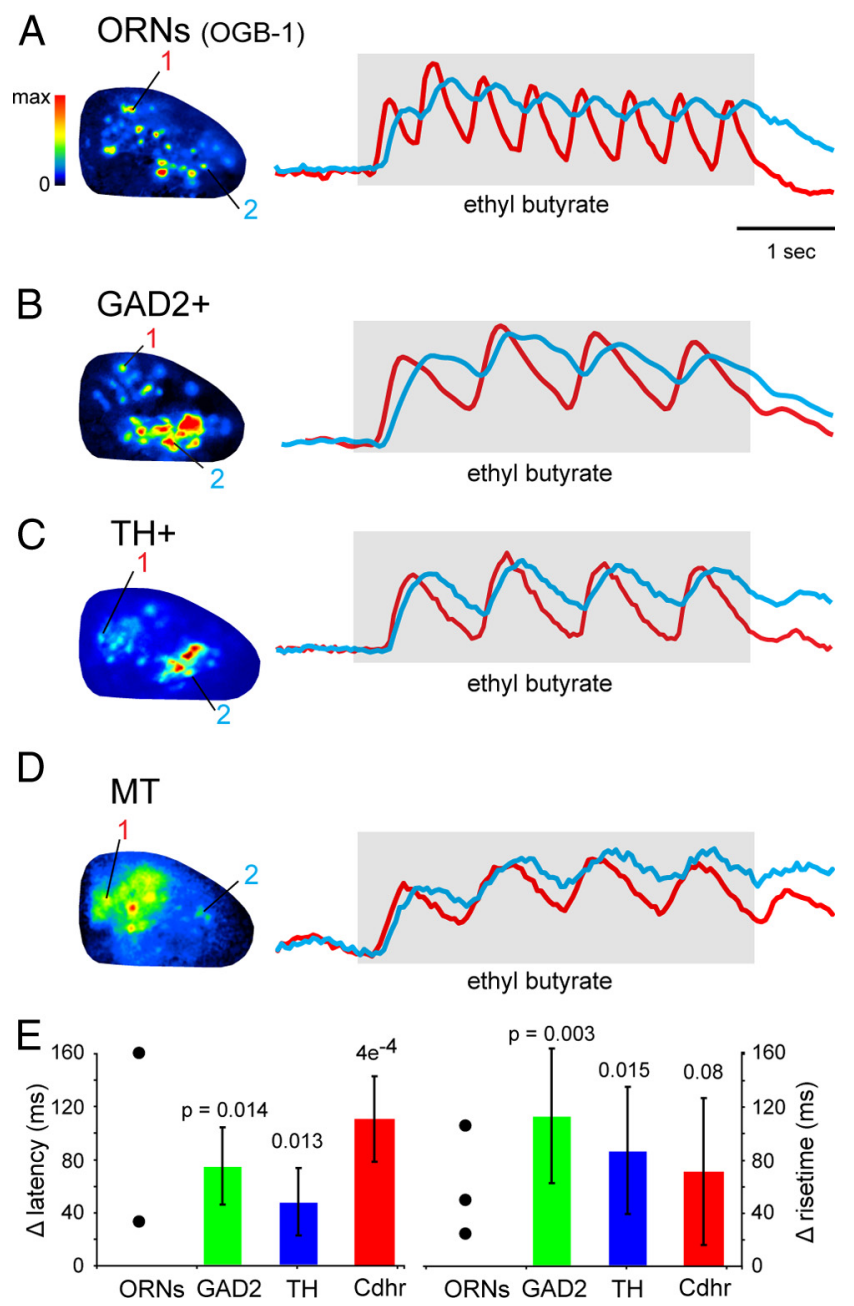

Figure 6. Inhalation-linked dynamics of odorant responses are similar across $O B$ neuron types. Response maps (left) and traces (right) showing calcium signals evoked in response to artificial inhalation of the odorant ethyl butyrate imaged from $0 \operatorname{RNs}(\boldsymbol{A}), \mathrm{GAD2}^{+}$neurons $(\boldsymbol{B})$, $\mathrm{TH}^{+}$neurons $(\boldsymbol{C})$, and $\mathrm{PCdh} 21^{+} \mathrm{MT}$ cells $(\boldsymbol{D})$. Traces show fluorescence from one caudal-lateral region of interest $(1$, red) and one anteromedial region of interest $(2$, cyan). Inhalation pulses (data not shown) were $150 \mathrm{~ms}$ in duration and were repeated at $2 \mathrm{~Hz}$ for ORNs $(\boldsymbol{A})$ and $1 \mathrm{~Hz}$ for all postsynaptic neurons $(\boldsymbol{B}-\boldsymbol{D})$. $\boldsymbol{E}$, Plots of difference $(\Delta)$ in latency relative to inhalation (left) or rise time (right; time from $10-90 \%$ of peak) between caudal-lateral and anteromedial glomeruli imaged from $0 \operatorname{RNs}\left(n=2\right.$ mice for latency, 3 for rise-time), $\operatorname{GAD2}^{+}$neurons $(n=6)$, $\mathrm{TH}^{+}$neurons $(n=5)$, and PCdh21 ${ }^{+}$MT cells $(n=6)$. See Materials and Methods for details. Error bars indicate SD. Circles in ORN column indicate values from each mouse and only include data not already reported in Spors et al. (2006). In all cases, the caudal-lateral glomerulus reaches peak levels earlier and decays faster than the anterior-medial glomerulus. The $p$ value (paired $t$ test) for comparison between anteromedial and caudal-lateral $O B$ is shown above each bar. The calcium reporter was OGB-1 dextran for ORNs and GCaMP3 for all postsynaptic neurons. Traces are averages of four trials.

was prominent in GCaMP signals imaged in GAD2-Cre, TH-Cre, and PCdh21-Cre mice (Fig. $6 B-D$ ). Response latencies relative to inhalation onset were similar for GCaMP signals originating in all three cell types and for presynaptic $\mathrm{Ca}^{2+}$ signals measured from ORNs: ORNs, $180 \pm 31 \mathrm{~ms}$ ( $n=5$ mice, 183 responses); GAD2 ${ }^{+}$, $172 \pm 42 \mathrm{~ms}$ ( $n=9$ mice, 958 responses $) ; \mathrm{TH}^{+}, 195 \pm 28 \mathrm{~ms}$ ( $n=3$ mice; 320 responses); PCdh $21^{+}, 202 \pm 66 \mathrm{~ms}(n=15$ mice, 1096 responses).

Odorant- and glomerulus-specific differences in the dynamics of the inhalation-evoked GCaMP signal were apparent in all three cell types (Fig. 6B-D) and mimicked those measured from ORN terminals (Fig. $6 A$ ) in terms of both the magnitude and the to- pography of latency differences. For example, in GAD2-Cre, THCre, and PCdh21-Cre mice, the latency and rise times of the GCaMP signal evoked by ethyl butyrate were significantly faster for caudal-lateral glomeruli than for anteromedial glomeruli and showed a greater modulation between inhalations (Fig. 6E), a result identical to that reported with presynaptic imaging (Spors et al., 2006). Therefore, despite their slower dynamics relative to synthetic $\mathrm{Ca}^{2+}$ indicators (Akerboom et al., 2012), GCaMP3 and GCaMP5G are able to report relative timing differences in odorant-evoked activity on a scale thought to be relevant for coding odor information (Cury and Uchida, 2010; Shusterman et al., 2011). In addition, the close correspondence in these dynamics between presynaptic and three different sources of postsynaptic activity suggest that the intrinsic and inhalation-driven dynamics of sensory input persist through multiple stages of synaptic processing in the $\mathrm{OB}$.

\section{Modulation of $\mathrm{OB}$ neuron responsiveness by wakefulness and anesthesia}

Wakefulness can dramatically alter response properties and excitability of $\mathrm{OB}$ neurons compared with anesthetized states (Rinberg et al., 2006; Vincis et al., 2012), and a recent report using GCaMP imaging demonstrated that MT and granule cells are differentially modulated by wakefulness (Kato et al., 2012). To address how odor representations among MT cells and additional cell types are modulated by wakefulness at the population level, we imaged odorant-evoked activity among GAD2 ${ }^{+}$PG cells, $\mathrm{TH}^{+}$SA cells, and PCdh $21^{+}$MT cells using epifluorescence imaging in the awake, head-fixed mouse. For comparison, and to evaluate for the first time the temporal structure of sensory input to the $\mathrm{OB}$ of the awake mouse, we also performed imaging from ORNs loaded with a synthetic $\mathrm{Ca}^{2+}$ indicator.

Imaging presynaptic $\mathrm{Ca}^{2+}$ signals from ORNs in wild-type mice revealed robust (up to $15 \% \Delta F / F$ ) odorant-evoked calcium signals that were transient and tightly coupled to inhalation, with onset latencies of $153 \pm 61 \mathrm{~ms}(n=6$ mice, 158 sniffs; Fig. $7 A)$, similar to presynaptic ORN signals imaged in head-fixed rats (Verhagen et al., 2007). Presynaptic calcium signals evoked by inhalation in the absence of odorant could not be detected. In both GAD2-Cre and TH-Cre mice expressing virally driven GCaMP5G or reporter-driven GCaMP3, odorants evoked strong fluorescence increases $(15-60 \% \Delta F / F)$ that were also tightly coupled to inhalation. Onset latencies were similar to those imaged from ORNs $\left(\mathrm{GAD}^{+}, 161 \pm 59 \mathrm{~ms}, n=3\right.$ mice, 481 sniffs; $\mathrm{TH}^{+}$, $144 \pm 15 \mathrm{~ms}, n=4$ mice, 615 sniffs). In both mouse lines, responses were reliable across repeated odorant presentations (Fig. $7 \mathrm{~B}, \mathrm{C})$. Fluorescence decreases in response to odorant were never observed. In both lines, inhalation-evoked signals in anteromedial regions showed less modulation by the respiratory cycle, slower decay during the exhalation phase, and more summation across successive inhalations of odorant (Fig. $7 \mathrm{~B}, \mathrm{C}$ ), recapitulating temporal response patterns seen under anesthesia (Fig. 6). In most regions, respiratory modulation was apparent at breathing rates of $3-4 \mathrm{~Hz}$ typical of quiescent mice. Both GAD2 ${ }^{+}$and $\mathrm{TH}^{+}$ GCaMP5G signals also showed respiratory modulation in the absence of odorant, consisting of small inhalation-driven responses apparent in a few regions of the $\mathrm{OB}$ (Fig. 7B). More striking, however, were larger fluorescence increases evoked by single large-amplitude inhalations, as well as longer-lasting increases linked to occasional bouts of high-frequency sniffing (Fig. $7 B, C)$.

In contrast, in awake PCdh21-Cre mice expressing GCaMP3 $(n=2)$ or GCaMP5G $(n=2)$ in MT cells, the fluorescence 
response to odorant differed dramatically from that observed in anesthetized mice, consisting predominately of decreases in fluorescence of up to $12 \% \Delta F / F$, superimposed with transient, small-amplitude increases ( $\max$ of $3 \% \Delta F / F$; Fig. $7 D$ ). Responses could consist of multiple phases of increase or decrease and often included distinct responses to odorant offset, all of which were reliably repeated across presentations (Fig. 7D, Fig. 8). Respiratory modulation in the absence of odorant was observed occasionally and, similar to $\mathrm{GAD}_{2}{ }^{+}$and $\mathrm{TH}^{+}$GCaMP5G signals, bursts of high-frequency sniffing elicited widespread fluorescence increases (data not shown). Although different odorants evoked distinct spatiotemporal patterns of fluorescence changes across the dorsal OB, in general, fluorescence increases were localized to restricted foci and decreases were spatially widespread (Fig. 8). In PCdh21-Cre mice expressing virally driven GCaMP3 in MT cells $(n=2$ animals), odorant-evoked responses consisted entirely of widespread fluorescence decreases, with no detectable increases ( $n=5$ odorants tested, 10 sessions).

To compare differences between response patterns in awake versus anesthetized states directly, we briefly (1-3 min) anesthetized head-fixed mice with isoflurane and then imaged GCaMP signals immediately after removal of isoflurane and as the animal returned to the waking state over the next 1-2 min. In GAD2-Cre and $\mathrm{TH}-\mathrm{Cre}$ mice, isoflurane-induced anesthesia led to a substantial decrease in the amplitude of odorant-evoked responses (Fig. 9A,B), with $\mathrm{GAD} 2{ }^{+}$responses and $\mathrm{TH}^{+}$responses being reduced to $45 \pm$ $23 \%(n=3$ mice $)$ and $27 \pm 17 \%(n=4$ mice), respectively, of initial peak amplitudes. Isoflurane also led to a decrease in resting fluorescence across the dorsal $\mathrm{OB}$ to $78 \pm 7 \%\left(\mathrm{GAD}^{+}\right)$and $80 \pm 2 \%$ $\left(\mathrm{TH}^{+}\right)$of initial values. In PCdh2 $1^{+} \mathrm{MT}$ cells, the effect of short-term isoflurane anesthesia also reduced resting fluorescence to $77 \pm 3 \%$ of awake levels ( $n=4$ mice), but its effect on odorant-evoked responses was more complex, consisting primarily of a reduction or elimination of the widespread fluorescence decreases apparent in the awake state, along with an emergence of slower fluorescence increases in focal locations (Fig. 9C). In all lines, both odorant-evoked and resting fluorescence returned to preanesthesia levels within 1-3 min after removal of isoflurane.

One difficulty in comparing sensory-evoked signals between awake and anesthetized animals is that the strength and frequency of inhalation also varies substantially between states. Therefore, in a separate set of animals, we compared responses at different depths of isoflurane anesthesia while using artificial inhalation to sample odorants consistently. Anesthesia depth af-

A ORNs (OGB-1)

B GAD2+

C $\mathrm{TH}+$

D MT
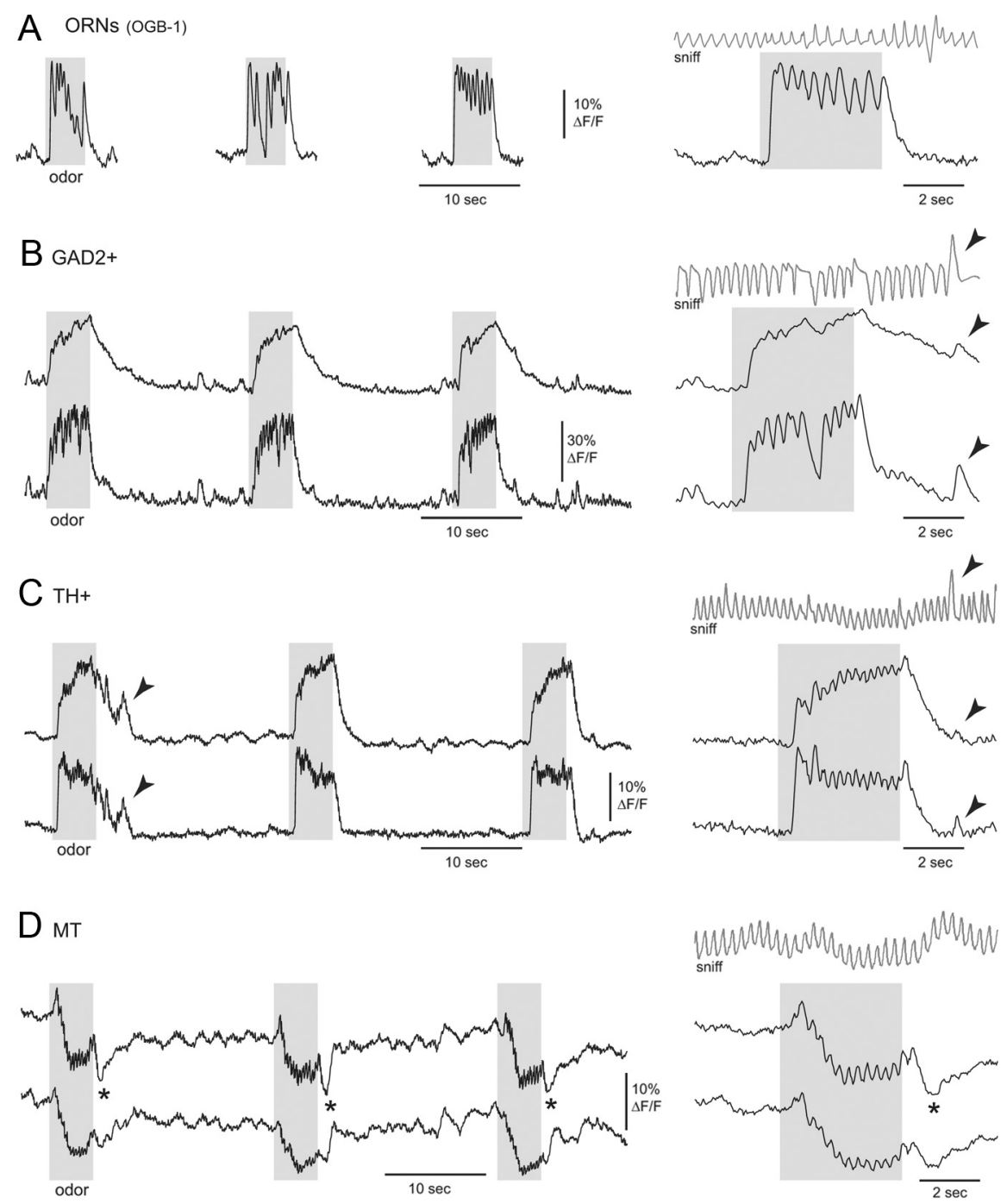

Figure 7. $\quad O B$ neurons show robust odorant-driven and respiration-modulated responses in the awake mouse. Examples of spontaneous and odorant-evoked calcium signals imaged from ORNs using 0GB-1 dextran $(\boldsymbol{A}), \mathrm{GAD2}{ }^{+}$neurons $(\boldsymbol{B})$, $\mathrm{TH}^{+}{ }^{+}$neurons $(\boldsymbol{C})$, and $\mathrm{PCdh} 21^{+}$MT cells $(\boldsymbol{D})$ in the awake, head-fixed mouse. Top trace shows respiration measured via intranasal pressure $(\boldsymbol{A})$ or thermocouple $(\boldsymbol{B}-\boldsymbol{D})$, with inhalation up in all cases. Left traces show three successive odorant presentations (black bar) separated by $20-30$ s; records are continuous in $(\boldsymbol{B}-\boldsymbol{D})$. Right traces show a single odorant presentation with expanded time-scale.

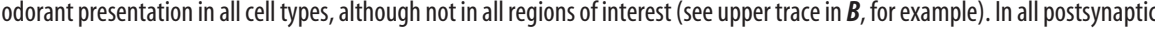
euron types, bouts of high-frequency sniffing or a single strong sniff (arrowheads) drive fluorescence increases in the absence of . Responses in ORNs, $\mathrm{GAD2}^{+}$, and $\mathrm{TH}^{+}$neurons consist solely of fluorescence increases, whereas responses in $\mathrm{PCdh} 21^{+}$ MT cells consist of dynamic sequences of brief increases and stronger and longer-lasting decreases, including "off" responses (asterisks). The calcium reporter for all postsynaptic neurons ( $\boldsymbol{B}-\boldsymbol{D})$ is GCaMP5G.

fected response magnitude significantly in all three cell types (one-way ANOVA, GAD2-Cre, $F_{(2,87)}=135.3, p \ll 0.001$; THCre, $F_{(2,57)}=86.9 ; p \ll 0.001$, PCdh21-Cre, $F_{(2,45)}=39.8, p \ll$ $0.001)$. Interestingly, the direction of the effect of anesthesia differed among cell types, with decreasing anesthesia depth leading to increased response amplitudes in $\mathrm{GAD}^{+}{ }^{+}$and $\mathrm{TH}^{+}$neurons (Fig. 9D,E) and decreased responses in PCdh $21^{+}$MT cells (Fig. $9 F)$. Resting fluorescence was also modestly dependent on anesthesia depth, with fluorescence under $2 \%$ isoflurane at $85 \pm 8 \%$ $\left(\mathrm{GAD}^{+}{ }^{+}, n=4\right.$ mice $), 90 \pm 4 \%\left(\mathrm{TH}^{+}, n=5\right.$ mice $)$, and $88 \pm 6 \%$ (Pcdh $21^{+}, n=4$ mice) of the levels seen under $0.5 \%$ isoflurane. Therefore, anesthesia alters the responsiveness of OB neurons in a manner that is distinct for different cell types and is independent of its effects on respiration. 


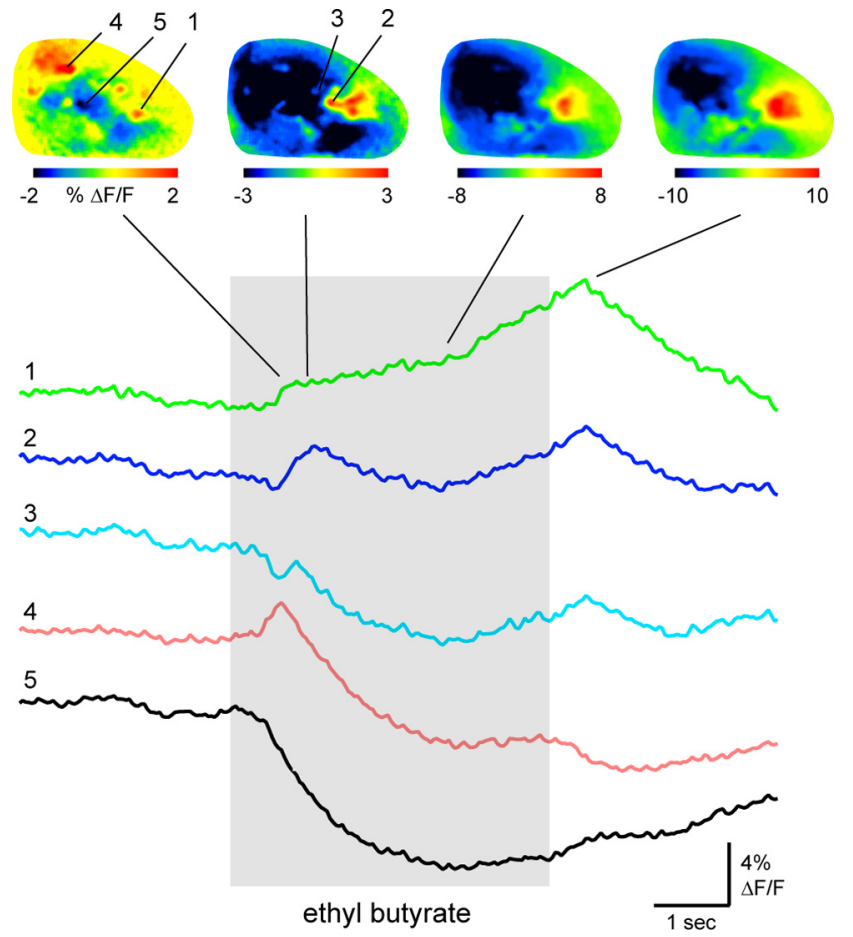

Figure 8. Complex spatiotemporal sequences of excitation and inhibition among MT cells revealed by GCaMP5 imaging in the awake mouse. Shown are fluorescence traces (bottom) and snapshots of odorant-evoked response maps (top) taken at different times during odorant presentation in an awake, head-fixed PCdh2 $21^{+}$mouse expressing GCaMP5G in MT cells. Images show maps of fluorescence changes relative to the preodor "baseline" taken from the indicated times. Each map is scaled so that zero $\Delta F$ is in the middle of the pseudocolor range (green). Fluorescence traces are averages of $6-12$ pixels taken from the indicated regions and show distinct sequences of fluorescence decrease or increase. Images are taken from the average of four presentations aligned on odorant presentation and so do not reflect inhalationdriven transients.

\section{Discussion}

In the present study, we used optical reporters of neural activity and genetic tools for cell-type-specific expression to begin investigating early olfactory processing at the single-neuron and population level in anesthetized and awake mice. We compared the responses of genetically specified classes of OB neurons, including MT cells that project to the olfactory cortex and, for the first time to our knowledge, PG and SA cells that mediate intraglomerular and interglomerular processing, with those of sensory afferents. We also demonstrate our ability to achieve combinatorial selectivity of expression based on both genetic markers and axonal projection target using readily available recombinant AAV-type viral vectors.

We characterized the fidelity of GCaMP3 and GCaMP5G as reporters of spiking activity in $\mathrm{OB}$ neurons, adding to previous characterizations of these reporters in other brain areas (Tian et al., 2009; Borghuis et al., 2011; Yamada et al., 2011; Akerboom et al., 2012). Although not tested here, those studies reported no significant impact of GCaMP expression on the electrophysiological or evoked response properties of GCaMP-expressing neurons using either the long-term reporter expression or short-term viral expression modes. GCaMP fluorescence changes could be related quantitatively to changes in spike rate by accounting for the dynamics of the GCaMP reporter and for any nonlinearity in the relationship between spike frequency and fluorescence. In a given neuron, this relationship is robust, allowing for accurate inference of spiking activity over a relatively large dynamic range,
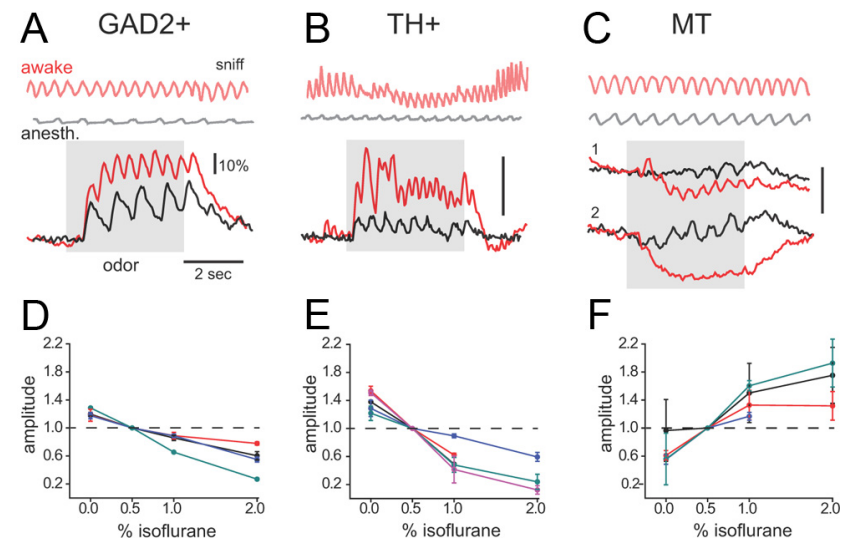

Figure 9. Differential effects of anesthesia on PG, SA, and MT cell odorant responses $\boldsymbol{A}-\boldsymbol{C}$, Traces showing GCaMP5G fluorescence evoked by odorant presentation imaged from the same region of interest in an awake, head-fixed mouse (red trace) and, $<5$ min later, after brief application of is oflurane anesthesia (black trace). Isoflurane was removed $\sim 60$ $s$ before imaging. Top traces show respiration measured via intranasal thermocouple during wakefulness (upper) and anesthesia (lower). Traces are shifted slightly to be aligned on the first inhalation after odorant onset. Inhalation-evoked fluorescence increases in $\mathrm{GAD2}^{+}(\boldsymbol{A})$ and $\mathrm{TH}^{+}$neurons $(\boldsymbol{B})$ are attenuated after anesthesia, whereas strong fluorescence decreases in $\mathrm{PCdh} 21^{+}$MT cells are replaced by slow (but small) increases $(\boldsymbol{C})$. C, Traces from two different regions of interest. Dashed line indicates preodor baseline. $\boldsymbol{D}-\boldsymbol{F}$, Effect of anesthesia depth on odorant-evoked GCaMP responses imaged in $\mathrm{GAD}^{+}(\boldsymbol{D}), \mathrm{TH}^{+}(\boldsymbol{E})$, and $\mathrm{PC} \mathrm{Ch} 21^{+} \mathrm{MT}(\boldsymbol{F})$ cells. Plots show peak inhalationevoked signals imaged under isoflurane concentrations ranging from $0-2 \%$ ( $0 \%$ levels were measured $<60 \mathrm{~s}$ after adjusting the vaporizer and returned to $0.5 \%$ immediately after the imaging trials). Each plot shows mean \pm SD responses imaged across one to six regions of interest in each preparation, with values normalized to those at $0.5 \%$ isoflurane. In all preparations, is oflurane was delivered via a tracheotomy tube and odorant was sampled (in air) via artificial inhalation (see Materials and Methods). Both GAD2 ${ }^{+}$( $n=4$ mice) and $\mathrm{TH}^{+}$responses ( $n=5$ mice) decrease with increasing isoflurane concentration, whereas $\mathrm{PCdh} 21^{+}$responses $(n=4$ mice) increase. See text for statistical analysis.

a feature that is useful for detecting and quantifying changes in activity under different conditions, for example, due to different stimuli, activation of modulatory centers, or changes in behavioral state. A caveat is that the time constants and linearity of the fluorescence/spiking relationship can vary for the same neuron type depending on expression modality and can vary for the same reporter expressed in different neuron types. Therefore, it is important to characterize these parameters in a given population and with a given expression modality.

GCaMP signals could be measured reliably from dendritic processes and from cell bodies extending from the glomerular layer to as deep as the mitral cell layer in vivo. Simultaneous imaging from multiple somata revealed that, among MT cells, spontaneous fluorescence transients occurred synchronously among a subset of cells, which is consistent with sister mitral cells innervating the same glomerulus (Christie and Westbrook, 2006; Dhawale et al., 2010). In response to odorant stimulation, individual MT cells showed distinct odorant specificities and diverse temporal patterns of activation, which is consistent with a recent report using the same GCaMP imaging approach (Kato et al., 2012). In contrast, GAD2 ${ }^{+} \mathrm{PG}$ cells and $\mathrm{TH}^{+} \mathrm{SA}$ cells, while odorant specific, showed little spontaneous activity and substantially less temporal diversity. The relatively simple response dynamics of PG and SA cells appeared to be distinct from those reported for granule cells, which show a large range of response latencies when imaged using GCaMP3 (Kato et al., 2012). These observations highlight the diversity of response properties among different $O B$ subtypes and high- 
light the importance of recording from identified circuit elements to understand how sensory inputs are transformed within the $\mathrm{OB}$ in vivo.

\section{Topography and dynamics of odor representations across cell type}

At the population level, patterns of odorant-evoked calcium signals were similar for ORN inputs, GAD2 ${ }^{+} \mathrm{PG}$ cells, $\mathrm{TH}^{+} \mathrm{SA}$ cells, and PCdh $21^{+}$MT cells. For all cell types, odorant response maps included foci located in stereotyped topographic domains (Uchida et al., 2000; Takahashi et al., 2004; Bozza et al., 2009; Pacifico et al., 2012), and increasing the odorant concentration increased response amplitudes and recruited more widespread signals. In addition, small temporal differences in the inhalationlinked dynamics of ORN inputs to topographically distinct glomeruli were also apparent in GCaMP signals imaged from each cell type.

One explanation for these similarities is that GCaMP signals imaged from the glomerular layer mainly report synaptic input from ORNs rather than output from postsynaptic neurons. This explanation seems unlikely for PG cells given their compact, uniglomerular morphology (Kiyokage et al., 2010) and given that GCaMP signals imaged directly from PG cell somata showed similar amplitude and dynamics as those imaged from the glomerular neuropil. Calcium signals in the apical tuft of MT cells are more likely to diverge from patterns of spike output. However, action potentials in MT cells back-propagate and drive $\mathrm{Ca}^{2+}$ influx into the apical tuft in vivo (Charpak et al., 2001; Debarbieux et al., 2003), and in vitro experiments suggest that synaptically driven $\mathrm{Ca}^{2+}$ influx generates significantly smaller $\mathrm{Ca}^{2+}$ signals in the apical tuft than do action potentials (Zhou et al., 2006), indicating that apical calcium signals at least partially reflect MT spiking. Finally, PG and MT cells transmit information within the glomerular neuropil via dendrodendritic synapses and, therefore, $\mathrm{Ca}^{2+}$ signals imaged from these neurons are likely reliable indicators of local output affecting glomerular processing (Murphy et al., 2005).

The substantial GCaMP signals arising from MT cell lateral dendrites also implies that such signals should have been apparent from SA cells, because their somata and extensive interglomerular projections remain confined to the glomerular layer (Kiyokage et al., 2010). It is therefore notable that GCaMP signals imaged from SA cells showed significantly less spread across the dorsal OB than did those imaged from MT cells, because SA cell processes and MT cell lateral dendrites have similarly sparse branching patterns and SA processes are more superficial. Potential explanations for this difference include differences in calcium channel expression or action potential propagation along SA cell processes versus MT cell lateral dendrites. Indeed, whether the extensive interglomerular branching of SA cells consists of axonal or dendritic processes remains unclear (Kiyokage et al., 2010). Direct visualization of lateral signal propagation along SA versus MT cell processes using two-photon imaging may be necessary to resolve this question.

The circuit elements of the OB network imaged here have been proposed to play multiple roles in transforming afferent odor representations, including sparsening representations through intraglomerular or interglomerular inhibition, concentration-invariant normalization of $\mathrm{OB}$ output patterns, and decorrelating sensory inputs and OB outputs (Friedrich and Laurent, 2001; Cleland and Sethupathy, 2006; Cleland et al., 2007; Yaksi et al., 2007; Cleland et al., 2012). Two-photon imaging of individual MT cells did reveal evidence for a decorrelation between ORN inputs and OB outputs, because some cells displayed temporal response patterns that were distinct from ORN input patterns and from neighboring cells. In addition, population-level MT responses in the awake mouse showed sparse excitation and temporal complexity not apparent in sensory inputs or in PG or SA cell responses. Further work will be necessary to understand how such transformations emerge from the OB network, for example, by simultaneously imaging activity in different neuron subtypes using spectrally distinct GCaMP variants (Zhao et al., 2011; Ohkura et al., 2012).

\section{Effects of anesthesia and wakefulness on $O B$ neuron responses}

Our data expand on a recent report showing that anesthesia strongly and differentially modulates the responsiveness of MT and granule cells (Kato et al., 2012). In the present study, we confirmed that wakefulness leads to a reduction in excitatory MT cell responses and also found that PG and SA cell responses are enhanced during wakefulness, an effect similar to that seen for granule cells (Kato et al., 2012) and one consistent with the hypothesis that the strength of glomerular inhibition is an important regulator of MT cell response properties (Gire and Schoppa, 2009; Shao et al., 2012). We also found that this modulation is rapid, occurring within the 1-2 min necessary for the removal of brief isoflurane anesthesia, and that it is independent of changes in inhalation strength. Therefore, three major classes of GABAergic OB interneurons, $\mathrm{PG}$ cells, SA cells, and granule cells (Kato et al., 2012), show enhanced responsiveness in the waking versus the anesthetized state. The source of modulation of PG and SA cell excitability during wakefulness may be distinct from that affecting granule cell excitability, because a major source of granule cell modulation, centrifugal inputs from olfactory cortex (Balu et al., 2007; Gao and Strowbridge, 2009), does not strongly innervate the glomerular layer. Therefore, multiple circuit mechanisms likely underlie the reduced MT cell responsiveness during wakefulness compared with anesthesia. Similarly, distinct circuit mechanisms likely underlie the modulation of MT response properties during different behavioral states or as a function of experience (Kato et al., 2012).

We also found that odorant-evoked MT population responses in the awake mouse consisted of sparse and transient increases and, notably, widespread decreases in fluorescence. We interpret the fluorescence decreases that dominated awake MT response maps as reflecting inhibition of ongoing MT activity. The ability to report both excitation and inhibition was dependent on the choice of reporter: GCaMP3-expressing MT cells showed only decreases in the awake mouse (but showed increases under anesthesia), whereas GCaMP5G-expressing neurons exhibited responses in both directions. The predominance of inhibition in MT GCaMP signals during wakefulness suggests that inhibitory pathways in the $\mathrm{OB}$ are critical in shaping $\mathrm{OB}$ output patterns. The ability to optically map this inhibition among distinct cell types in vivo will be useful in further understanding the functional organization of processing within the $\mathrm{OB}$.

\section{References}

Akerboom J, Chen TW, Wardill TJ, Tian L, Marvin JS, Mutlu S, Calderón NC, Esposti F, Borghuis BG, Sun XR, Gordus A, Orger MB, Portugues R, Engert F, Macklin JJ, Filosa A, Aggarwal A, Kerr RA, Takagi R, Kracun S, et al. (2012) Optimization of a GCaMP calcium indicator for neural activity imaging. J Neurosci 32:13819-13840. CrossRef Medline

Atasoy D, Aponte Y, Su HH, Sternson SM (2008) A FLEX switch targets Channelrhodopsin-2 to multiple cell types for imaging and long-range circuit mapping. J Neurosci 28:7025-7030. CrossRef Medline 
Aungst JL, Heyward PM, Puche AC, Karnup SV, Hayar A, Szabo G, Shipley MT (2003) Centre-surround inhibition among olfactory bulb glomeruli. Nature 426:623-629. CrossRef Medline

Balu R, Pressler RT, Strowbridge BW (2007) Multiple modes of synaptic excitation of olfactory bulb granule cells. J Neurosci 27:5621-5632. CrossRef Medline

Borghuis BG, Tian L, Xu Y, Nikonov SS, Vardi N, Zemelman BV, Looger LL (2011) Imaging light responses of targeted neuron populations in the rodent retina. J Neurosci 31:2855-2867. CrossRef Medline

Bozza T, McGann JP, Mombaerts P, Wachowiak M (2004) In vivo imaging of neuronal activity by targeted expression of a genetically encoded probe in the mouse. Neuron 42:9-21. CrossRef Medline

Bozza T, Vassalli A, Fuss S, Zhang JJ, Weiland B, Pacifico R, Feinstein P, Mombaerts P (2009) Mapping of class I and class II odorant receptors to glomerular domains by two distinct types of olfactory sensory neurons in the mouse. Neuron 61:220-233. CrossRef Medline

Carey RM, Verhagen JV, Wesson DW, Pírez N, Wachowiak M (2009) Temporal structure of receptor neuron input to the olfactory bulb imaged in behaving rats. J Neurophysiol 101:1073-1088. CrossRef Medline

Chaigneau E, Tiret P, Lecoq J, Ducros M, Knöpfel T, Charpak S (2007) The relationship between blood flow and neuronal activity in the rodent olfactory bulb. J Neurosci 27:6452-6460. CrossRef Medline

Chaput MA (1986) Respiratory-phase-related coding of olfactory information in the olfactory bulb of awake freely-breathing rabbits. Physiol Behav 36:319-324. CrossRef Medline

Charpak S, Mertz J, Beaurepaire E, Moreaux L, Delaney K (2001) Odorevoked calcium signals in dendrites of rat mitral cells. Proc Natl Acad Sci U S A 98:1230-1234. CrossRef Medline

Christie JM, Westbrook GL (2006) Lateral Excitation within the Olfactory Bulb 10.1523/JNEUROSCI.4791-05.2006. J Neurosci 26:2269-2277. CrossRef Medline

Cleland TA, Sethupathy P (2006) Non-topographical contrast enhancement in the olfactory bulb. BMC Neurosci 7:7. CrossRef Medline

Cleland TA, Johnson BA, Leon M, Linster C (2007) Relational representation in the olfactory system. Proc Natl Acad Sci U S A 104:1953-1958. CrossRef Medline

Cleland TA, Chen S-YT, Hozer KW, Ukatu HN, Wong KJ, Zheng F (2012) Sequential mechanisms underlying concentration invariance in biological olfaction. Frontiers in Neuroengineering 4.

Cury KM, Uchida N (2010) Robust odor coding via inhalation-coupled transient activity in the mammalian olfactory bulb. Neuron 68:570-585. CrossRef Medline

Debarbieux F, Audinat E, Charpak S (2003) Action potential propagation in dendrites of rat mitral cells in vivo. J Neurosci 23:5553-5560. Medline

Dhawale AK, Hagiwara A, Bhalla US, Murthy VN, Albeanu DF (2010) Nonredundant odor coding by sister mitral cells revealed by light addressable glomeruli in the mouse. Nat Neurosci 13:1404-1412. CrossRef Medline

Fletcher ML, Masurkar AV, Xing J, Imamura F, Xiong W, Nagayama S, Mutoh H, Greer CA, Knöpfel T, Chen WR (2009) Optical imaging of postsynaptic odor representation in the glomerular layer of the mouse olfactory bulb. J Neurophysiol 102:817-830. CrossRef Medline

Friedrich RW, Laurent G (2001) Dynamic optimization of odor representations by slow temporal patterning of mitral cell activity. Science 291:889894. CrossRef Medline

Gao Y, Strowbridge BW (2009) Long-term plasticity of excitatory inputs to granule cells in the rat olfactory bulb. Nat Neurosci 12:731-733. CrossRef Medline

Gire DH, Schoppa NE (2009) Control of on/off glomerular signaling by a local GABAergic microcircuit in the olfactory bulb. J Neurosci 29:1345413464. CrossRef Medline

Gong S, Doughty M, Harbaugh CR, Cummins A, Hatten ME, Heintz N, Gerfen CR (2007) Targeting Cre recombinase to specific neuron populations with bacterial artificial chromosome constructs. J Neurosci 27: 9817-9823. CrossRef Medline

Hayar A, Karnup S, Ennis M, Shipley MT (2004) External tufted cells: A major excitatory element that coordinates glomerular activity. J Neurosci 24:6676-6685. CrossRef Medline

Kato HK, Chu MW, Isaacson JS, Komiyama T (2012) Dynamic sensory representations in the olfactory bulb: modulation by wakefulness and experience. Neuron 76:962-975. CrossRef Medline

Kiyokage E, Pan YZ, Shao Z, Kobayashi K, Szabo G, Yanagawa Y, Obata K, Okano H, Toida K, Puche AC, Shipley MT (2010) Molecular identity of periglomerular and short axon cells. J Neurosci 30:1185-1196. CrossRef Medline

Kosaka T, Kosaka K (2008) Tyrosine hydroxylase-positive GABAergic juxtaglomerular neurons are the main source of the interglomerular connections in the mouse main olfactory bulb. Neurosci Res 60:349-354. CrossRef Medline

Lillis KP, Eng A, White JA, Mertz J (2008) Two-photon imaging of spatially extended neuronal network dynamics with high temporal resolution. J Neurosci Methods 172:178-184. CrossRef Medline

Ma J, Lowe G (2010) Correlated firing in tufted cells of mouse olfactory bulb. Neuroscience 169:1715-1738. CrossRef Medline

Ma L, Qiu Q, Gradwohl S, Scott A, Yu EQ, Alexander R, Wiegraebe W, Yu CR (2012) Distributed representation of chemical features and tunotopic organization of glomeruli in the mouse olfactory bulb. Proc Natl Acad Sci U S A

Madisen L, Zwingman TA, Sunkin SM, Oh SW, Zariwala HA, Gu H, Ng LL, Palmiter RD, Hawrylycz MJ, Jones AR, Lein ES, Zeng H (2010) A robust and high-throughput Cre reporting and characterization system for the whole mouse brain. Nat Neurosci 13:133-140. CrossRef Medline

Mitsui S, Igarashi KM, Mori K, Yoshihara Y (2011) Genetic visualization of the secondary olfactory pathway in Tbx21 transgenic mice. Neural systems and circuits 1:5. CrossRef Medline

Murphy GJ, Darcy DP, Isaacson JS (2005) Intraglomerular inhibition: signaling mechanisms of an olfactory microcircuit. Nat Neurosci 8:354-364. CrossRef Medline

Nagai Y, Sano H, Yokoi M (2005) Transgenic expression of Cre recombinase in mitral/tufted cells of the olfactory bulb. Genesis 43:12-16. CrossRef Medline

Ohkura M, Sasaki T, Kobayashi C, Ikegaya Y, Nakai J (2012) An improved genetically encoded red fluorescent $\mathrm{Ca}^{2+}$ indicator for detecting optically evoked action potentials. PLoS One 7:e39933. CrossRef Medline

Pacifico R, Dewan A, Cawley D, Guo C, Bozza T (2012) An olfactory subsystem that mediates high-sensitivity detection of volatile amines. Cell Reports 2:76-88. CrossRef Medline

Parrish-Aungst S, Shipley MT, Erdelyi F, Szabo G, Puche AC (2007) Quantitative analysis of neuronal diversity in the mouse olfactory bulb. J Comp Neurol 501:825-836. CrossRef Medline

Pologruto TA, Sabatini BL, Svoboda K (2003) ScanImage: flexible software for operating laser scanning microscopes. BioMed Eng Online 2:13. CrossRef Medline

Rinberg D, Koulakov A, Gelperin A (2006) Sparse odor coding in awake behaving mice. J Neurosci 26:8857-8865. CrossRef Medline

Schoenfeld TA, Marchand JE, Macrides F (1985) Topographic organization of tufted cell axonal projections in the hamster main olfactory bulb: an intrabulbar associational system. J Comp Neurol 235:503-518. CrossRef Medline

Schoppa NE, Westbrook GL (2001) Glomerulus-specific synchronization of mitral cells in the olfactory bulb. Neuron 31:639-651. CrossRef Medline

Shao Z, Puche AC, Liu S, Shipley MT (2012) Intraglomerular inhibition shapes the strength and temporal structure of glomerular output. J Neurophysiol.

Shipley M, Ennis M, Puche A (2004) The olfactory system. In: The rat nervous system, Ed 3 (Paxinos G, ed), pp 922-963. San Diego: Elsevier.

Shipley MT, Adamek GD (1984) The connections of the mouse olfactory bulb: a study using orthograde and retrograde transport of wheat germ agglutinin conjugated to horseradish peroxidase. Brain Res Bull 12:669688. CrossRef Medline

Shusterman R, Smear MC, Koulakov AA, Rinberg D (2011) Precise olfactory responses tile the sniff cycle. Nat Neurosci 14:1039-1044. CrossRef Medline

Soucy ER, Albeanu DF, Fantana AL, Murthy VN, Meister M (2009) Precision and diversity in an odor map on the olfactory bulb. Nat Neurosci 12:210-220. CrossRef Medline

Spors H, Wachowiak M, Cohen LB, Friedrich RW (2006) Temporal dynamics and latency patterns of receptor neuron input to the olfactory bulb. J Neurosci 26:1247-1259. CrossRef Medline

Takahashi YK, Kurosaki M, Hirono S, Mori K (2004) Topographic representation of odorant molecular features in the rat olfactory bulb. J Neurophysiol 92:2413-2427. CrossRef Medline

Tan J, Savigner A, Ma M, Luo M (2010) Odor information processing by the 
olfactory bulb analyzed in gene-targeted mice. Neuron 65:912-926. CrossRef Medline

Taniguchi H, He M, Wu P, Kim S, Paik R, Sugino K, Kvitsiani D, Fu Y, Lu J, Lin Y, Miyoshi G, Shima Y, Fishell G, Nelson SB, Huang ZJ (2011) A resource of Cre driver lines for genetic targeting of GABAergic neurons in cerebral cortex. Neuron 71:995-1013. CrossRef Medline

Tian L, Hires SA, Mao T, Huber D, Chiappe ME, Chalasani SH, Petreanu L, Akerboom J, McKinney SA, Schreiter ER, Bargmann CI, Jayaraman V, Svoboda K, Looger LL (2009) Imaging neural activity in worms, flies and mice with improved GCaMP calcium indicators. Nat Meth 6:875881. CrossRef Medline

Uchida N, Takahashi YK, Tanifuji M, Mori K (2000) Odor maps in the mammalian olfactory bulb: domain organization and odorant structural features. Nat Neurosci 3:1035-1043. CrossRef Medline

Verhagen JV, Wesson DW, Netoff TI, White JA, Wachowiak M (2007) Sniffing controls an adaptive filter of sensory input to the olfactory bulb. Nat Neurosci 10:631-639. CrossRef Medline

Vincis R, Gschwend O, Bhaukaurally K, Beroud J, Carleton A (2012) Dense representation of natural odorants in the mouse olfactory bulb. Nat Neurosci 15:537-539. CrossRef Medline

Wachowiak M, Cohen LB (2001) Representation of odorants by receptor neuron input to the mouse olfactory bulb. Neuron 32:723-735. CrossRef Medline

Wachowiak M, Shipley MT (2006) Coding and synaptic processing of sensory information in the glomerular layer of the olfactory bulb. Semin Cell Dev Biol 17:411-423. CrossRef Medline

Wellis DP, Scott JW (1990) Intracellular responses of identified rat olfactory bulb interneurons to electrical and odor stimulation. J Neurophysiol 64:932-947. Medline

Wesson DW, Carey RM, Verhagen JV, Wachowiak M (2008) Rapid encoding and perception of novel odors in the rat. PLoS Biol 6:e82. CrossRef Medline

Xiong W, Chen WR (2002) Dynamic gating of spike propagation in the mitral cell lateral dendrites. Neuron 34:115-126. CrossRef Medline

Yaksi E, Judkewitz B, Friedrich RW (2007) Topological reorganization of odor representations in the olfactory bulb. PLoS Biol 5:e178. CrossRef Medline

Yamada Y, Michikawa T, Hashimoto M, Horikawa K, Nagai T, Miyawaki A, Hausser M, Mikoshiba K (2011) Quantitative comparison of genetically encoded $\mathrm{Ca}^{2+}$ indicators in cortical pyramidal cells and cerebellar Purkinje cells. Front Cell Neurosci 2011;5:18. CrossRef Medline

Yokoi M, Mori K, Nakanishi S (1995) Refinement of odor molecule tuning by dendrodendritic synaptic inhibition in the olfactory bulb. Proc Natl Acad Sci U S A 92:3371-3375. CrossRef Medline

Zariwala HA, Borghuis BG, Hoogland TM, Madisen L, Tian L, De Zeeuw CI, Zeng H, Looger LL, Svoboda K, Chen TW (2012) A Cre-dependent GCaMP3 reporter mouse for neuronal imaging in vivo. J Neurosci 32: 3131-3141. CrossRef Medline

Zhao Y, Araki S, Wu J, Teramoto T, Chang YF, Nakano M, Abdelfattah AS, Fujiwara M, Ishihara T, Nagai T, Campbell RE (2011) An expanded palette of genetically encoded $\mathrm{Ca}(2)(+)$ indicators. Science 333:1888 1891. CrossRef Medline

Zhou Z, Xiong W, Zeng S, Xia A, Shepherd GM, Greer CA, Chen WR (2006) Dendritic excitability and calcium signalling in the mitral cell distal glomerular tuft. Eur J Neurosci 24:1623-1632. CrossRef Medline 